\title{
Experimental and numerical investigation of the buckling performance of tubular glass columns under compression

\author{
Mohd Khairul Kamarudin ${ }^{a}$, Mustafasanie M. Yusoff ${ }^{b}$,Peter Disney ${ }^{c}$, Gerard A.R. Parke \\ ${ }^{a}$ Universiti Teknologi MARA (UiTM), Faculty of Civil Engineering, Shah Alam,40450, Malaysia \\ ${ }^{b}$ Universiti Sains Malaysia, School of Civil Engineering, Nibong Tebal,14300, Malaysia \\ ${ }^{c}$ University of Surrey, Department of Civil and Environmental Engineering, Guildford, GU27XH, United Kingdom
}

\begin{abstract}
This study investigates the buckling performance of tubular glass columns under axial compression. A total of two cases are considered (i) single glass tubular column and (ii) bundled column constructed using structural silicone sealants. A series of compression test were carried out on different geometrical dimensions of these two cases to determine their failure mechanism, load carrying capacity and to evaluate the buckling performance. Prior to the load carrying capacity (LCC) that was measured at the ultimate, a distinctive remaining structural capacity (RSC) was characterized especially for bundled glass based on the first crack. The shear connection in the bundled system was justified in comparison to the monolithic glass. This study showed that the failure mechanisms depended strongly on the slenderness ratio of the columns and that the failure occurred either by crushing or by buckling depending on the lengths of the column. The scatter in the failure load for specimens that had a higher slenderness ratio was much lower than for those that had a lower slenderness ratio. In order to justify the variability of the glass strength, a Weibull statistical distribution was used. Finite element modelling (FE) based on the simplified Riks method was performed using ABAQUS v6.10 to compliment the test results and to provide methods of analysis which could be used as a guideline for structural
\end{abstract}


engineers to predict structural behaviour of tubular glass columns in general. An overestimation was predicted in the FE models which suggested modification of the imperfection factor.

\section{Introduction}

The dramatic increase in the use of glass in buildings has shown a significant requirement for glass to be used in a structurally efficient manner [1-3]. Structural elements made of glass create an interesting visual feature because of its uniqueness i.e. its transparent characteristics. However, the brittleness of glass may make it unsuitable, if used for a load bearing structural member. A significant understanding of how glass responds to loads is vital for structural engineers. At present, there is a large amount of published research concerned with the performance of glass structures [5-9] which indicates that in the correct environment structural glass shows good stability and build-ability.

In the early years of glass research [4], the focus was primarily on understanding the material properties of the several different types of glass, namely annealed, heat-strengthened and fully toughened glass. An innovation to increase the effectiveness and durability of structural glass was introduced, namely laminated glass. Laminated glass is a form of two or more layers of glass, bonded using an interlayer, created from the combination of those types of glass mentioned above. In general, two types of glass are produced; either float glass which is suitable for the construction industry, or borosilicate glass which is usually used for laboratory glassware. With safety issue being an important factor for structural glass, the maximum benefit of using glass must be obtained ensuring the avoidance of hazards to the public. Thus, laminated glass is

prospectively preferable since it has shown reliable performance in buildings [3]. Laminated cruciform glass columns of varying dimensions have been studied [5]. This type of cross-section 
shape eases the complexity of the beam-column connection. However, the inherent low torsional rigidity of cruciform columns is a disadvantage for structural glass applications when the elements are used in load-bearing structures.

A preliminary study on the buckling strength of glass elements has shown sensible results for a design method for glass members under compressive load [10]. Validation of Euler's buckling calculation for composite rectangular cross-sectional geometrical dimension has shown a reliable application for monolithic or laminated glass columns. A standard for glass buckling strength curves derived using the elastic, second order equations has been validated by buckling experiments and FE simulation. In [11-14], extensive verification works of composite rectangular cross-sectional glass column has been presented. A standardized Eurocode-based buckling curves has been proposed for a practical buckling verification of glass members under compression as well as in flexural torsional buckling. It was suggested that a proper verification of glass columns in response to the failure mechanism could be predicted by taking into account the effect of initial geometrical imperfections and load/boundaries eccentricities.

Intensive research on glass structures has been undertaken at DELFT University of Technology, Netherlands with the research team there undertaking the ZAPPI research programs. Their initial focus was on glass beams and plates. However, research into the behaviour of glass column was initiated later, specifically on laminated tubular glass columns [15]. The study on laminated tubular glass columns has focused on investigating the load carrying capacity of the column and the effect of the interlayer (in-situ resin) to ensure the glass elements remained cohesive. The study was extended to investigate the safe failure behaviour of the laminated glass columns after the first crack was initiated during loading [16]. In comparison to the shape proposed, the tubular glass column is of interest to achieve higher torsional rigidity 
and is structurally effective for glass applications. It can be considered as the innovative design concept for structural glass.

A very interesting principal has been characterized at the ABT-Office, Arnhem, Netherlands in which 7 tubular glass columns of size $30 \mathrm{~mm}$ diameters were bundled together with a resin to form a column. Inspired by the laminated glass arrangement to introduce redundancy into structural glass, bundling the glass columns by applying resin could be an alternative to constructing using single glass columns while keeping the transparency characteristics in the structural system. Lack of experimental data is made visible in respect to the structural behaviour (failure mechanism, buckling strength etc.) of bundled glass columns except for the numerical modelling in designing the glass element proposed in [17]. Hence, the performance of bundled glass columns under compression load along with the evaluation of the existing design methods would be of an interesting subject of research in structural tubular glass columns. Previous research on structural glass usually involved a series of experimental programs and very little work using finite element analysis was undertaken. Therefore, a quest to provide information on the structural behaviour of transparent tubular glass columns of various forms by undergoing a series of experimental programs followed by finite element analysis is paramount.

The main objective of this study was to investigate the structural behaviour of tubular single glass columns (SGC) and bundled glass columns (BGC) under compression by pursuing the following; a physical testing scheme to establish failure mechanisms, load carrying capacity and buckling performance, and calibration of an FE model validated by the physical tests. The investigation was carried out by performing an experimental program of compression tests based on the Veer test arrangement [16]. Apart from evaluating the load carrying capacity (LCC), one 
of the key objectives behind the work is to provide a fail-safe response for glass columns. A failsafe response is a load resistance mechanism in the glass columns where, once the first crack appears during increasing load, the remaining load carrying capacity (remaining structural capacity - RSC) is sufficient to carry all imposed loads. This was first introduced in [18] which appropriately justified the ability of structural glass to carry loads especially for the layered/laminated arrangement. In regard to the experimental results, a finite element analysis was calibrated to simulate the buckling behaviour of the columns. The following factors are studied and discussed: (i) effects of geometrical dimensions and (ii) effects of shear connections in the bundling system. The geometrical arrangements of the glass columns are illustrated in Fig.1.
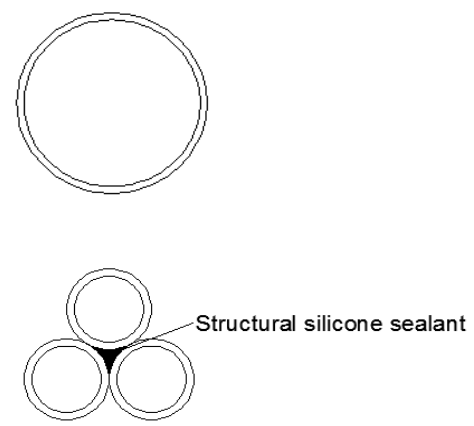

(a) SGC - single-piece hollow section of tubular glass column with a standard length of $1500 \mathrm{~mm}$ to the manufacturer specification

(b) BGC - combination of three single-piece hollow section of tubular glass column with a standard length of $1500 \mathrm{~mm}$, bundled together using structural silicon sealants

Fig. 1: The geometrical arrangements of (a) single glass columns (SGC) and (b) bundled-glass columns (BGC)

In this paper, based on [19], an experimental program was designed to provide a better understanding of the behaviour of structural tubular glass columns under compressive load. Various diameter sizes of the SGC and BGC are used in the experimental program. The study is limited to testing an annealed-borosilicate glass due to its affordability and extensive use by 
previous researchers. The experimental program comprises of two phases of compression test. The first phase is with the SGC specimens where five different sizes of diameter with specified wall thickness were tested. The second phase is designed to evaluate the structural behaviour of BGC with only two different sizes of diameter with specified wall thicknesses investigated. A compression test was conducted to determine the failure mechanism, the load carrying capacity and the buckling strength for each specimen. A glass tube can be extremely efficient as it has a high buckling strength if it is of the correct geometry and the right dimensions [20].

Finite element analysis was used in order to establish a method for analysing the buckling behaviour of the tubular glass columns. The modelling was carried out using the ABAQUS package. Prior to the experimental work, an additional study was undertaken in which the glass surface was checked qualitatively to evaluate the existence of obvious micro-flaws which essentially contribute to the fragility of the glass. This has a bearing on the discrepancy between the theoretical strength and real strength of the glass elements. Column buckling curves are developed by carrying out a parametric study on single glass columns of different thickness to generate more results to form the design curves.

Research on glass structures is in its infancy and requires more effort to carry out studies that can give a wide range of possible outcomes. Through the development of structural glass in buildings, the laminated tubular glass columns have been the subject of study in recent years. However, little research output is available. In addition, the buckling performance of tubular glass columns has been studied but limited knowledge has surfaced. More findings need to be obtained especially for the basic single element of tubular glass columns to attain structural performance. This effort needs to be extended to study the structural behaviour of bundled glass 
columns inspired by the laminated glass arrangement as to complement the existing structure. This would certainly enhance the development of a standard practice for structural glass in buildings especially codes for glass columns, which are currently very limited, compared to steel and concrete standards.

\section{Experimental investigation}

Prior to the experimental work, measurements of the glass surface of the tubes to detect surface micro-cracks were carried out. Glass surface measurement was also carried out prior to the experimental work to qualitatively specify the micro-flaws inherent on the glass surface of tubes. This was vital in order to obtain the magnitude of significant sources of imperfections which contribute to the behaviour of the glass column in terms of its strength capacity. In this study, various diameters of the annealed-borosilicate glass SGC and BGC were used in the experimental program. The details of the specimens, compression test set-up and instrumentations of the experimental work are discussed in the next section.

\subsection{General description of the tubular hollow specimens}

The structural behaviour of the SGC was investigated. All specimens of the SGC were $1500 \mathrm{~mm}$ long. Five types of SGC were investigated with various outer diameters. While, a bundled glass column was formed by joining three SGCs with a standard length of $1500 \mathrm{~mm}$, bundled or bonded together using a structural silicon sealant. There were two types of BGC prepared and tested and the main parameter which varied in this test was the outer diameter of the glass columns. The structural silicone sealant used in the preparation of the specimens was 
manufactured from C-TEC N.I Limited which produced CT1 clear unique sealant and construction adhesive. This sealant provided unique adhesion on any material in most applications without the need for additional fixings. Structural silicone has been proven to be reliable and relatively inexpensive [21]. Since it was explicitly specified for interlayer material to be used in buildings, this type of sealant was deemed to be acceptable. It has received approval from the European Technical Approval Guideline (ETAG No.002) which is an essential requirement for glass structural applications [22]. The sealant was utilised due to its workable mechanical properties which was essentially to achieve soft structural connections in between the glass columns. Table 1 shows the material properties of the structural silicone sealant.

\section{Table 1}

Material properties of structural silicone sealant

\begin{tabular}{lccl}
\hline Characteristics & Symbol & Unit & Value \\
\hline Density & $\rho$ & $\mathrm{kg} / \mathrm{m}^{3}$ & 1542 \\
Young's modulus & $E$ & $\mathrm{MPa}$ & 1.72 \\
Poisson's ratio & $v$ & - & $\sim 0.50$ \\
Hardness* & - & - & 60 Shore A \\
Tensile strength & $f t$ & $\mathrm{MPa}$ & 2.65 \\
Elongation at rupture** & $\varepsilon \mathrm{t}$ & $\%$ & $>350$ \\
& & & \\
\hline
\end{tabular}

* According to DIN 53505

** According to DIN 53504

The process of fabricating BGC was undertaken entirely on-site and was not associated with any mechanical equipment. A piece of glass column was cleaned and degreased using a solvent to ensure the surface of the glass was free of grease, oil and dirt. This was important for the bonding to be firmly attached. A layer of the structural silicone sealant was applied on the first piece of the surface of the glass column along its length and this was followed by installing the 
second piece of the glass column on top of the applied sealant. A brief pressure on the columns by using hands was essential to attach the two tubes soundly together. Once the sealant reached its skin curing time which was about 8 minutes (according to the material specification), another layer of sealant was applied on top of the junction in between the two attached tubes and the third piece of the glass column was put on top of the sealant layer and again held by hand pressure. The full curing time was 24 hours. Fig. 2 shows the process of fabricating the BGC. The details of the specimens for SGC and BGC are given in Table 2. The length, outer diameter and wall thickness shown are the nominal dimension.

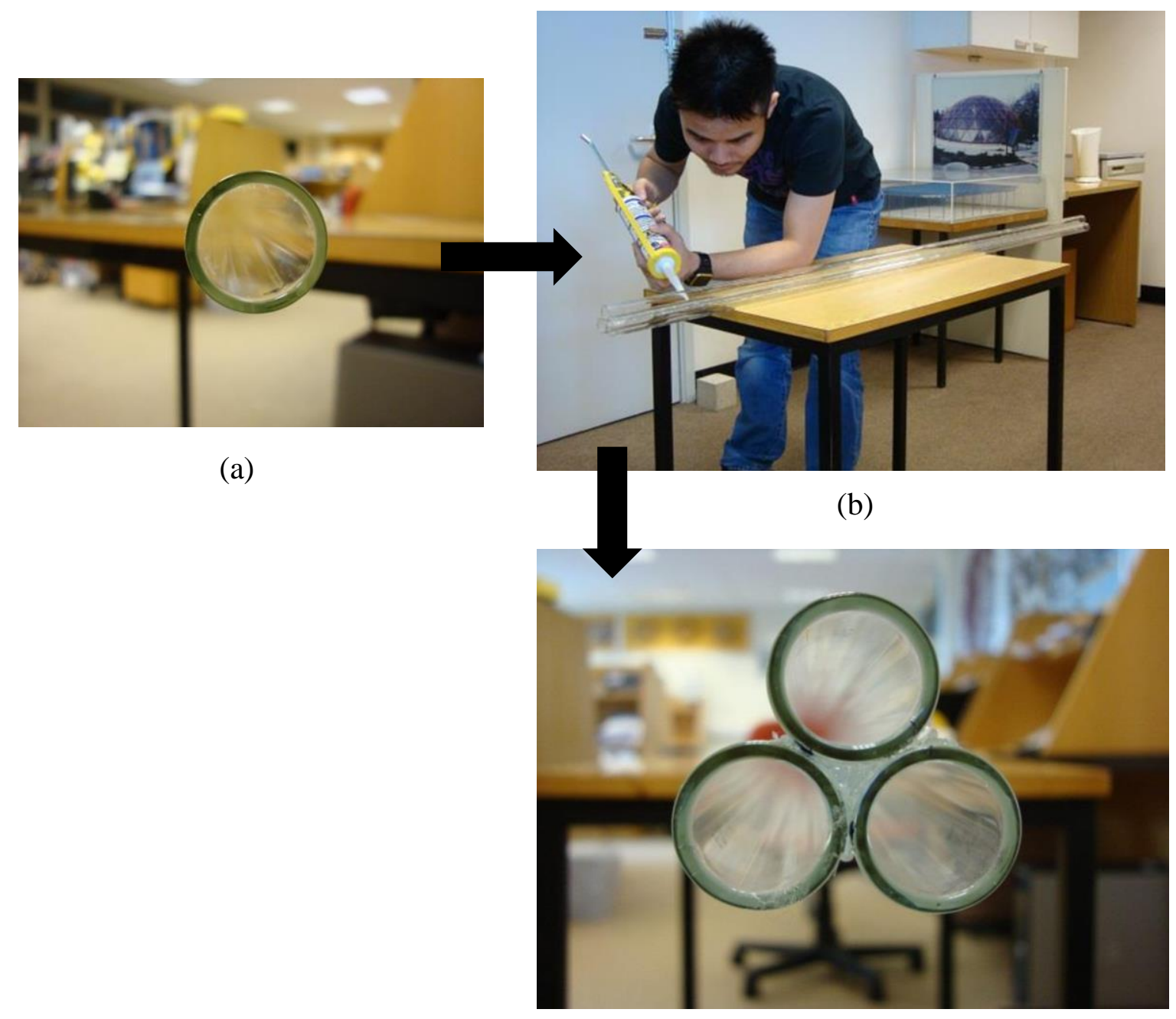


Fig. 2: BGC bonding process by using structural silicone sealant; applying structural silicone sealant; (c) BGC specimen after curing (c)

(a) SGC tube; (b) for 24 hours

Table 2

Details of specimens for SGC and BGC

\begin{tabular}{cccll}
\hline Type & Specimen & $\begin{array}{l}\text { Length, } \\
\text { L }(\mathrm{mm})\end{array}$ & $\begin{array}{l}\text { Outer } \\
\text { diameter, } \mathrm{d}_{\mathrm{o}} \\
(\mathrm{mm})\end{array}$ & $\begin{array}{l}\text { Wall } \\
\text { thickness, } \mathrm{t} \\
(\mathrm{mm})\end{array}$ \\
\hline T1-S & $1-4$ & 1500 & 60 & 7.0 \\
T2-S & $5-9$ & 1500 & 60 & 2.2 \\
T3-S & $10-14$ & 1500 & 50 & 1.8 \\
T4-S & $15-19$ & 1500 & 24 & 2.5 \\
T5-S & $20-24$ & 1500 & 20 & 1.8 \\
T6-B & $25-29$ & 1500 & 20 (per tube) & 1.8 (per tube) \\
T7-B & $30-34$ & 1500 & 24 (per tube) & 2.5 (per tube) \\
\hline d=outer diameter, $\mathrm{t}=$ wall thickness, T1, T2.=type, $\mathrm{S}=$ single, $\mathrm{B}=$ bundled
\end{tabular}

\subsection{Preliminary test measurements}

Initial measurements on straightness and out-of-roundness of the glass columns were carried out on each of the specimens to check the geometrical dimensions and tolerance of glass tube production. The tolerance has been specified by Schott-Duran borosilicate glass tubing in accordance to ISO 1101 - Geometrical Product Specifications (GPS). In order to measure the straightness of the tubes, sets of test measuring tools were used, namely V-blocks, dial test indicator (DTI) and digital height gauge (DHG). V-blocks were used to ensure the stability of the specimen when measurements were taken. A dial test indicator (DTI) and digital height gauge were the main tools to measure the straightness which were used by taking the height readings at three consecutive points relatively to the datum point (which was set to be 
zero) along the length of the specimen as shown in Fig. 3.

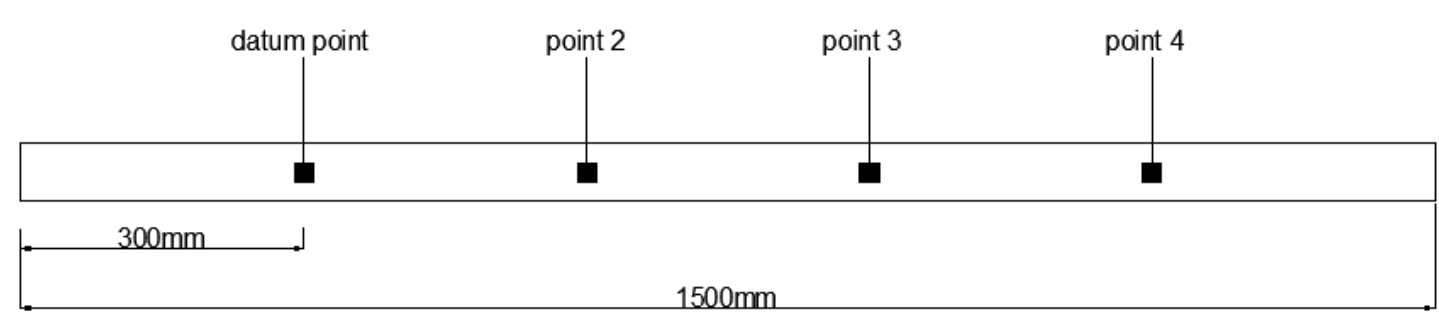

\section{Elevation view of glass column}

Fig. 3: Points of measurement in the method to measure straightness of the glass column.

The measurement was carried out at two specific angles, $90^{\circ}$ and $270^{\circ}$. According to ISO 1011 as quoted from the manufacturer specification, for an outer diameter of 30 to $100 \mathrm{~mm}$ (within test specimen's range diameter), the maximum difference in the height reading from points of measurement to the datum point should not exceed $2 \mathrm{~mm}$. The examples of readings taken during the measurement are presented in Table 3. Small deviations from the point of reference were found for the straightness measurement of the annealed glass which was generally lower than $0.5 \mathrm{~mm}$; hence suggesting almost null initial geometrical imperfections and the reliability of using nominal dimensions for the FE model. 
Table 3

Example readings taken during the measurement of straightness for T1 specimen 1.

\begin{tabular}{|c|c|c|c|c|c|c|c|}
\hline Tool & $\begin{array}{c}\text { Orientation } \\
\text { line }\end{array}$ & Point & $\begin{array}{l}\text { Reading } \\
1(\mathrm{~mm})\end{array}$ & $\begin{array}{l}\text { Reading } \\
2(\mathrm{~mm})\end{array}$ & $\begin{array}{l}\text { Reading } \\
3(\mathrm{~mm})\end{array}$ & $\begin{array}{l}\text { Average } \\
(\mathrm{mm})\end{array}$ & Straightness \\
\hline \multirow{8}{*}{ DHG } & \multirow{4}{*}{$90^{\circ}$} & 1(P.O.R) & 0 & 0 & 0 & - & \\
\hline & & 2 & -0.2 & -0.24 & -0.21 & -0.22 & fulfilled \\
\hline & & 3 & -0.33 & -0.32 & -0.38 & -0.34 & fulfilled \\
\hline & & 4 & -0.1 & -0.11 & -0.1 & -0.1 & fulfilled \\
\hline & \multirow{4}{*}{$270^{\mathrm{O}}$} & 1(P.O.R) & 0 & 0 & 0 & - & \\
\hline & & 2 & -0.25 & -0.21 & -0.22 & -0.23 & fulfilled \\
\hline & & 3 & -0.32 & -0.36 & -0.32 & -0.33 & fulfilled \\
\hline & & 4 & -0.11 & -0.1 & -0.1 & -0.1 & Fulfilled \\
\hline \multirow{8}{*}{ DTI } & \multirow{4}{*}{$90^{\mathrm{O}}$} & 1(P.O.R) & 0 & 0 & 0 & - & \\
\hline & & 2 & -0.2 & -0.22 & -0.23 & -0.22 & fulfilled \\
\hline & & 3 & -0.3 & -0.33 & -0.31 & -0.31 & fulfilled \\
\hline & & 4 & -0.1 & -0.11 & -0.11 & -0.11 & fulfilled \\
\hline & \multirow{4}{*}{$270^{\mathrm{O}}$} & 1(P.O.R) & 0 & 0 & 0 & - & \\
\hline & & 2 & -0.23 & -0.22 & -0.23 & -0.23 & fulfilled \\
\hline & & 3 & -0.36 & -0.34 & -0.32 & -0.34 & fulfilled \\
\hline & & 4 & -0.15 & -0.11 & -0.12 & -0.13 & Fulfilled \\
\hline
\end{tabular}

$\mathrm{DTI}=$ dial test indicator; $\mathrm{DHG}=$ digital height gauge; P.O.R=point of reference

\subsection{Test set-up and instrumentation}

A SATEC series $\mathrm{kN}$ Model universal testing machine from Instron was used for the test. The machine had a capacity of $600 \mathrm{kN}$ in compression and it allowed the load cell to be moved hydraulically at a constant rate of displacement. There were six strain gauges of Micro Measurements $120 \mu$ strain (CEA-06-240UZ-120). Each of these strain gauges had a working range of $2.095+0.5 \%$ gauge factor. The strain gauges were mounted on the surface of the glass at specific locations. The quarter bridge type strain gauge arrangement was used to measure the axial strain along the length of the glass and was connected by cables to the data logger. A 
StrainSmart data logger made by Micro Measurements was used to monitor and record the strain data obtained. The load cell fed continuous signals to the data logger via the amplifier and these signals were scanned to capture data at 1000 points per second. There were two kinds of deflection measurements taken in the test. In order to obtain axial deformation of the glass column, the measurement was directly obtained by the load cell movement of the testing machine which was controlled by the integrated data logger. At the start of each test, the testing machine was carefully calibrated over its full working range by using the advance control electronics which provided automatic recognition and calibration of transducers ensuring that proper instruments were used and that the data were reliable. The data logger was configured by Bluehill@ Universal Materials Software system which was a fully integrated suite of application modules for all types of material testing. All data were formatted to be stored into the Microsoft Excel program spreadsheets.

In order to obtain the lateral deformation at the mid-height of the column, three D/10000 C linear differential transformer transducers (LVDTs) were used. These transducers were carefully positioned at three different circumference points, namely $60^{\circ}, 180^{\circ}$ and $300^{\circ}$ orientations. The transducers were connected to the StrainSmart data logger and were calibrated via the respective amplifier using accurately measured slip gauges to set the displacement to zero. The transducer displacement was scanned at each pre-set interval to capture data again at 1000 data points per second. The glass column was setup at both ends on $4 \mathrm{~mm}$ thick neoprene rubber pads which, in turn was resting on a $10 \mathrm{~mm}$ poly-methyl methacrylate (PMMA usually known as 'Perspex') pads. Prior to the test, the supports (PMMA and rubber pad) at the top and bottom of the specimen were placed at the centre of the platen at both ends of the testing machine with regards to the central vertical alignment. The glass column was then placed 
according to the initial marks created on the supports to achieve a central vertical position. The glass column was fastened by lowering the load cell. To comply with the risk assessment and important safety reasons, an acrylic custom-made tube cover was put around the test set-up to prevent flying shards of glass that could cause hazards. Three designated holes on the acrylic tube cover were specified to allow the LVDTs to be placed at points that were marked around the mid length of the column. Pre-loading was applied usually 3 times by adopting about $3 \%$ of the theoretical buckling load. The specimen was then loaded at a constant $0.5 \mathrm{~mm} / \mathrm{min}$ axial displacement controlled rate. Fig.4 shows the schematic view of test set-up while Fig.5 illustrates the test set-up in the lab.

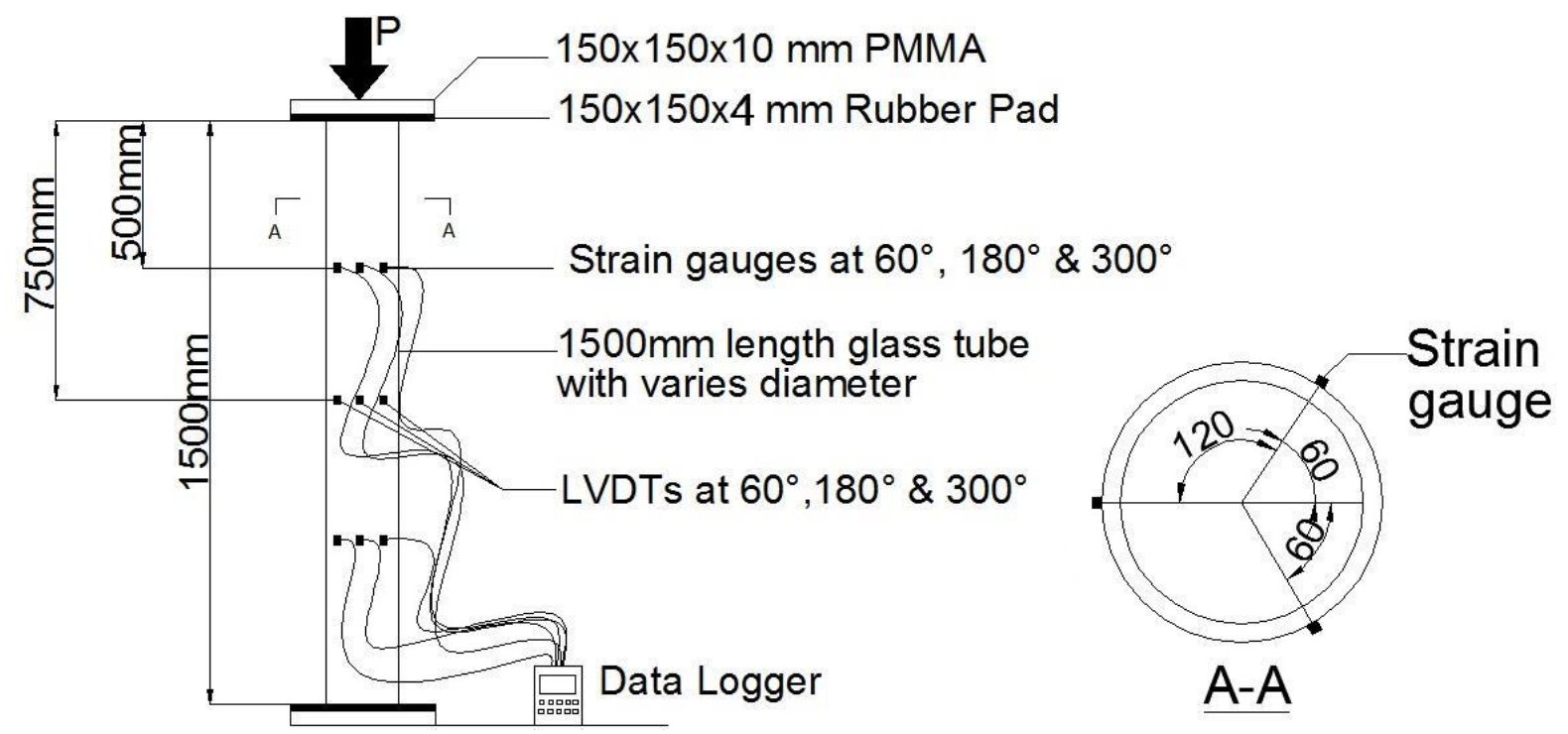

Fig. 4: Schematic view of test set-up 

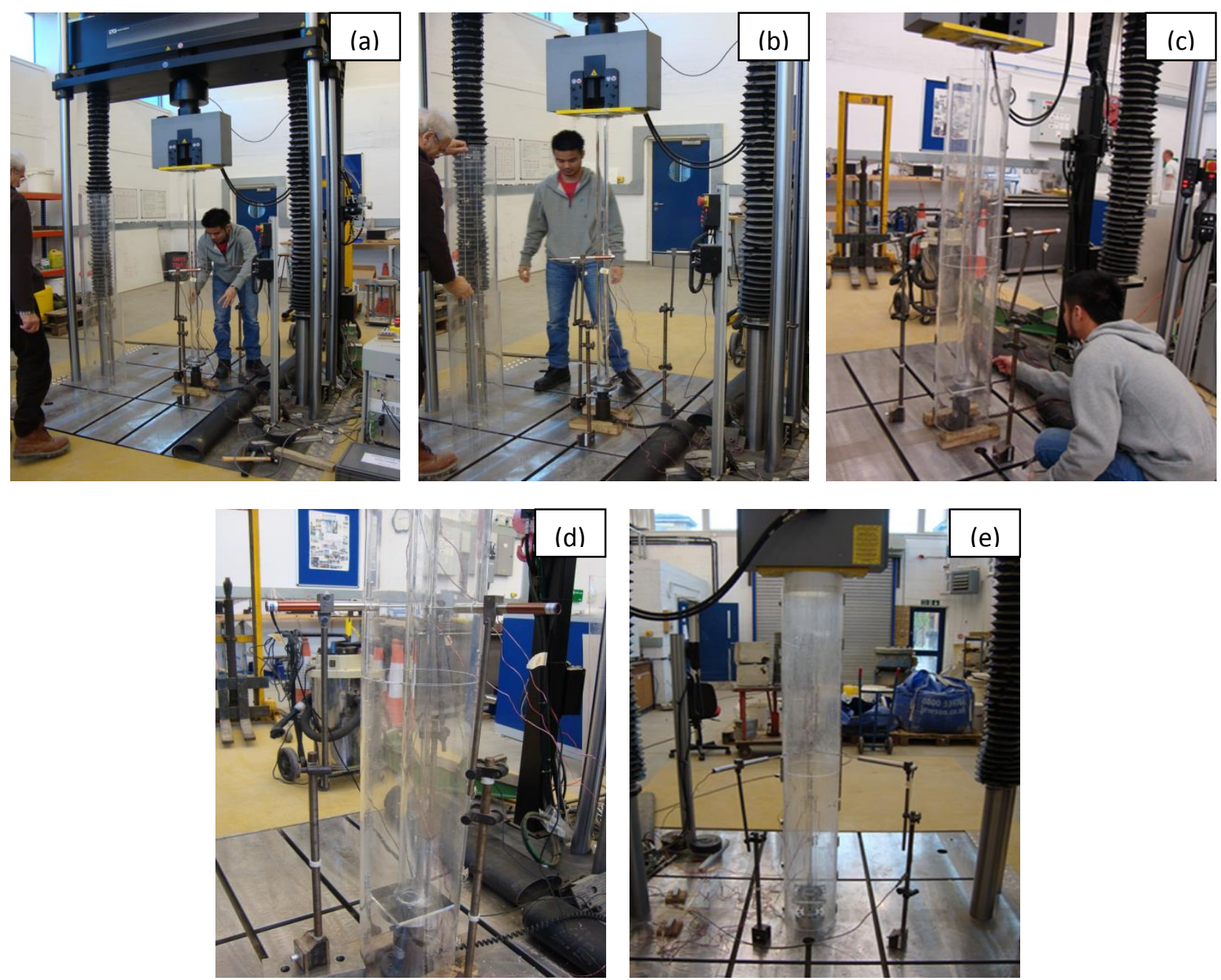

Fig.5: Test set-ups for a concentrically loaded tubular glass column, (a) setting in the glass column into test machine; (b) shielding the glass column with acrylic tube cover; (c) fixing the cables from the strain gauges to the data logger; (d) installing LVDTs at the middle of the column; and (e) final standing of the test set-up. 


\section{Comparative discussion of test results}

\subsection{Failure mechanism}

The failure mechanism is explained in terms of the physical appearance of the structure observed during and after conducting the test. The observation was made from the recorded video (a commercial video recorder with a recording speed of 25 frames per second). All specimens failed catastrophically. It was noticed from the videos that all specimens failed due to buckling except for $\mathrm{T} 1$ and $\mathrm{T} 2$ which failed due to crushing (compression). At the initial stage of the test, there was no measurable deformation along the length of the column. The failure mechanism during loading of specimens $\mathrm{T} 1$ and $\mathrm{T} 2$ was such that the first crack appeared as the load increased. The first crack was detected from the 'cracking' sound in the recorded video. The crack was recorded at a specific time as tabulated in Table 4. The video captured the initial crack at the bottom end of the glass column of specimens T1 and T2. The crack propagated in a linear fashion towards the direction of the mid length of the column. The final stage of the test of the aforementioned specimens showed that the glass columns shattered within the encapsulated acrylic tube cover. The failure mechanisms of the compression test for specimens $\mathrm{T} 1$ and $\mathrm{T} 2$ are shown in Fig.6. The crack propagated in the longitudinal axis direction signifying a crack running through the surface of the glass. Based on Table 4, the period between the appearance of the first crack and the ultimate failure in T1 was shorter than in T2. After the initial crack, the columns continued to resist load until failure occurred. During loading, glass splinters dropped from the top of the tube. The failure was triggered approximately at the bottom of the column and progressively cracked towards the top end of the column. All specimens in T1 and T2 showed no buckling deformation; instead cracking appeared to dominate the failure of the structural glass columns. The columns failed due to 
shortening by progressive cracking from the bottom end of the columns. With regards to the tabulated slenderness ratio data presented in Table 4, specimens $\mathrm{T} 1$ and $\mathrm{T} 2$ can be considered to be stocky with small slenderness ratios.

The failure mechanism for T3 was driven by the buckling deformation which dominated the failure of the structural glass column. Based on Table 4, the period between the first crack and the ultimate failure in T3 was short. It showed that the effect of the instantaneous failure was triggered in the glass column leading to structure vulnerability. Transverse deflection rapidly followed until the structure failed explosively. Buckling failure also dominated the failure mechanism in T4 and T5. The buckling mode shapes for T3, T4 and T5 are illustrated in Fig.7. However, no source of first crack or any cracks were recorded in T4 and T5. The glass columns did not shatter throughout the length but interestingly broke into several large parts at the middle of the columns. The post-failure condition of the T4 and T5 specimens were subjected to shattering at the middle region. The remaining end pieces were intact without having any source of crack line. Corresponding to the buckled mode shape of fixed ends, the effective length between the points of inflection (point of contra-flexure) should be in the range of $0.5 \mathrm{~L}(0.5 \times 1500 \mathrm{~mm}=750 \mathrm{~mm})$. It was found that for T4 specimens, most of the gap length of the broken glass measured at the mid-length of the column agreed with the theoretical effective length. While, for T5 specimens, most of the gap length did not fit well with the effective length. On average, the first crack occurred at least $50 \%$ from the ultimate load carrying capacity resisted by the glass column. 
Table 4

Summary of time and load at the first crack of SGC

\begin{tabular}{|c|c|c|c|c|c|c|}
\hline No. & Type & Specimen & $\begin{array}{c}\text { Time at } \\
\text { first } \\
\text { crack } \\
\text { (min) }\end{array}$ & $\begin{array}{c}\text { Load at } \\
\text { first } \\
\text { crack } \\
(\mathrm{kN})\end{array}$ & $\begin{array}{l}\text { Time at } \\
\text { ultimate } \\
\text { failure } \\
\text { (min) }\end{array}$ & $\begin{array}{l}\text { Maximum } \\
\text { failure load } \\
(\mathrm{kN})\end{array}$ \\
\hline 1 & \multirow{4}{*}{$\mathrm{T} 1$} & \multirow{4}{*}{$\begin{array}{l}\text { SGC- } \\
60 \_7.0\end{array}$} & NA & NA & 28.96 & 86.01 \\
\hline 2 & & & 27.10 & 117.32 & 28.46 & 125.19 \\
\hline 3 & & & 31.24 & 161.80 & 36.20 & 163.19 \\
\hline 4 & & & 23.36 & 35.66 & 28.55 & 47.48 \\
\hline 5 & \multirow{5}{*}{$\mathrm{T} 2$} & \multirow{5}{*}{$\begin{array}{l}\text { SGC- } \\
60 \_2.2\end{array}$} & 23.38 & 18.60 & 31.28 & 64.69 \\
\hline 6 & & & 26.34 & 16.80 & 34.03 & 60.11 \\
\hline 7 & & & 22.54 & 18.25 & 30.03 & 60.98 \\
\hline 8 & & & 21.43 & 15.67 & 33.24 & 76.70 \\
\hline 9 & & & 20.40 & 44.43 & 23.55 & 56.74 \\
\hline 10 & \multirow{5}{*}{$\mathrm{T} 3$} & \multirow{5}{*}{$\begin{array}{l}\text { SGC- } \\
50 \_1.8\end{array}$} & 27.21 & 52.00 & 29.78 & 57.04 \\
\hline 11 & & & 22.42 & 20.45 & 28.30 & 41.19 \\
\hline 12 & & & 28.42 & 42.41 & 33.12 & 53.31 \\
\hline 13 & & & 27.00 & 38.64 & 32.89 & 46.78 \\
\hline 14 & & & 20.48 & 13.14 & 33.05 & 51.99 \\
\hline 15 & \multirow{5}{*}{$\mathrm{T} 4$} & \multirow{5}{*}{$\begin{array}{l}\text { SGC- } \\
24 \_2.5\end{array}$} & $\mathrm{NA}$ & NA & 15.35 & 2.11 \\
\hline 16 & & & NA & NA & 18.61 & 1.95 \\
\hline 17 & & & NA & NA & 18.82 & 4.39 \\
\hline 18 & & & NA & NA & 19.85 & 3.83 \\
\hline 19 & & & NA & NA & 23.74 & 0.89 \\
\hline 20 & \multirow{5}{*}{$\mathrm{T} 5$} & \multirow{5}{*}{$\begin{array}{l}\text { SGC- } \\
20 \_1.8\end{array}$} & NA & NA & 13.34 & 0.95 \\
\hline 21 & & & NA & NA & 14.15 & 1.10 \\
\hline 22 & & & NA & NA & 14.86 & 1.07 \\
\hline 23 & & & NA & NA & 18.27 & 0.97 \\
\hline 24 & & & NA & NA & 17.60 & 1.02 \\
\hline
\end{tabular}

SGC-Single glass column; 20, 24, 50, 60-outer diameter; 1.8, 2.2, 2.5, 7.0-wall thickness 

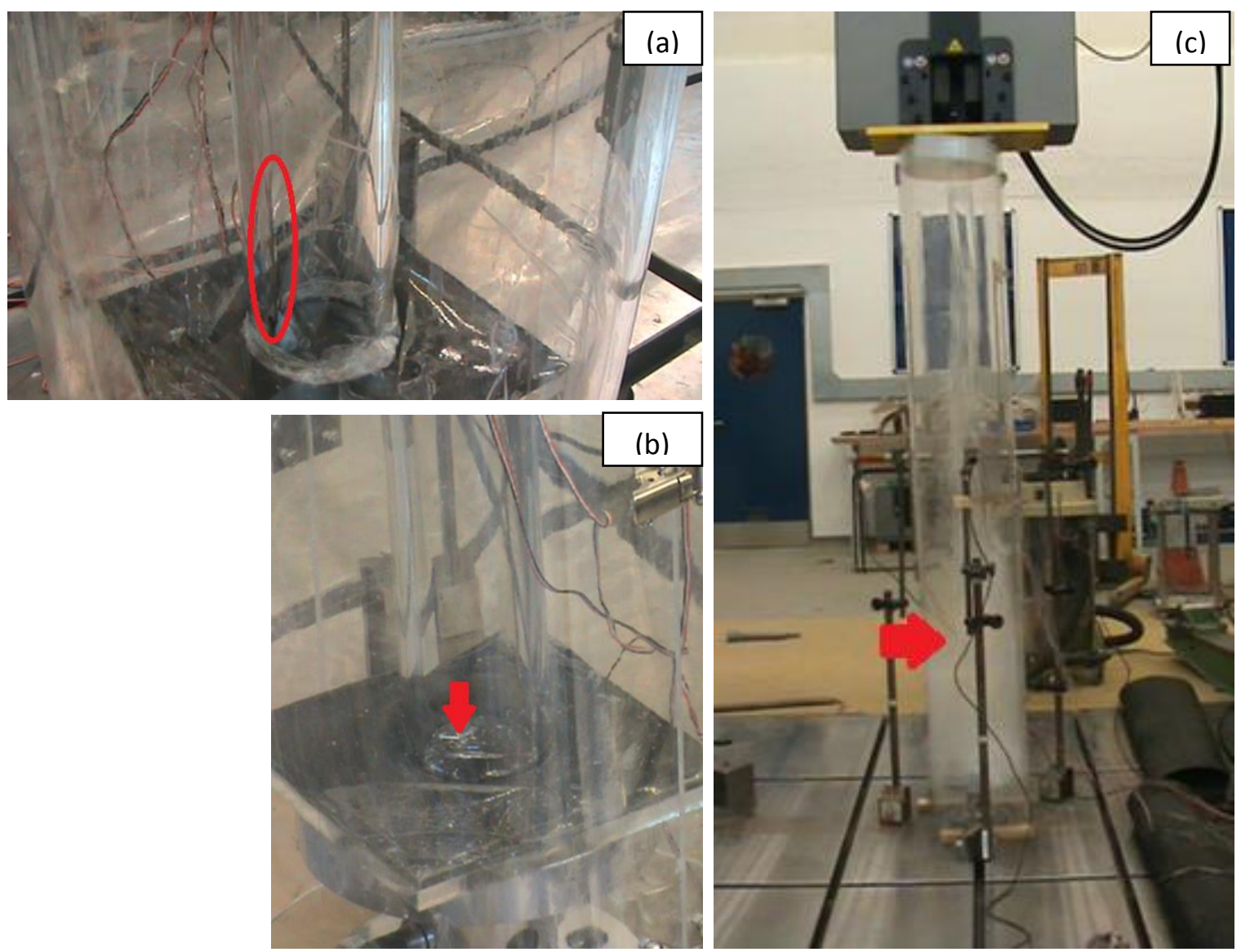

Fig. 6: Failure mechanisms of T1 and T2 of SGC, (a) the crack line propagating in a linear fashion rooting from the bottom end of the column; (b) dropped splinters from the top end; (c) glass column failed abruptly. 


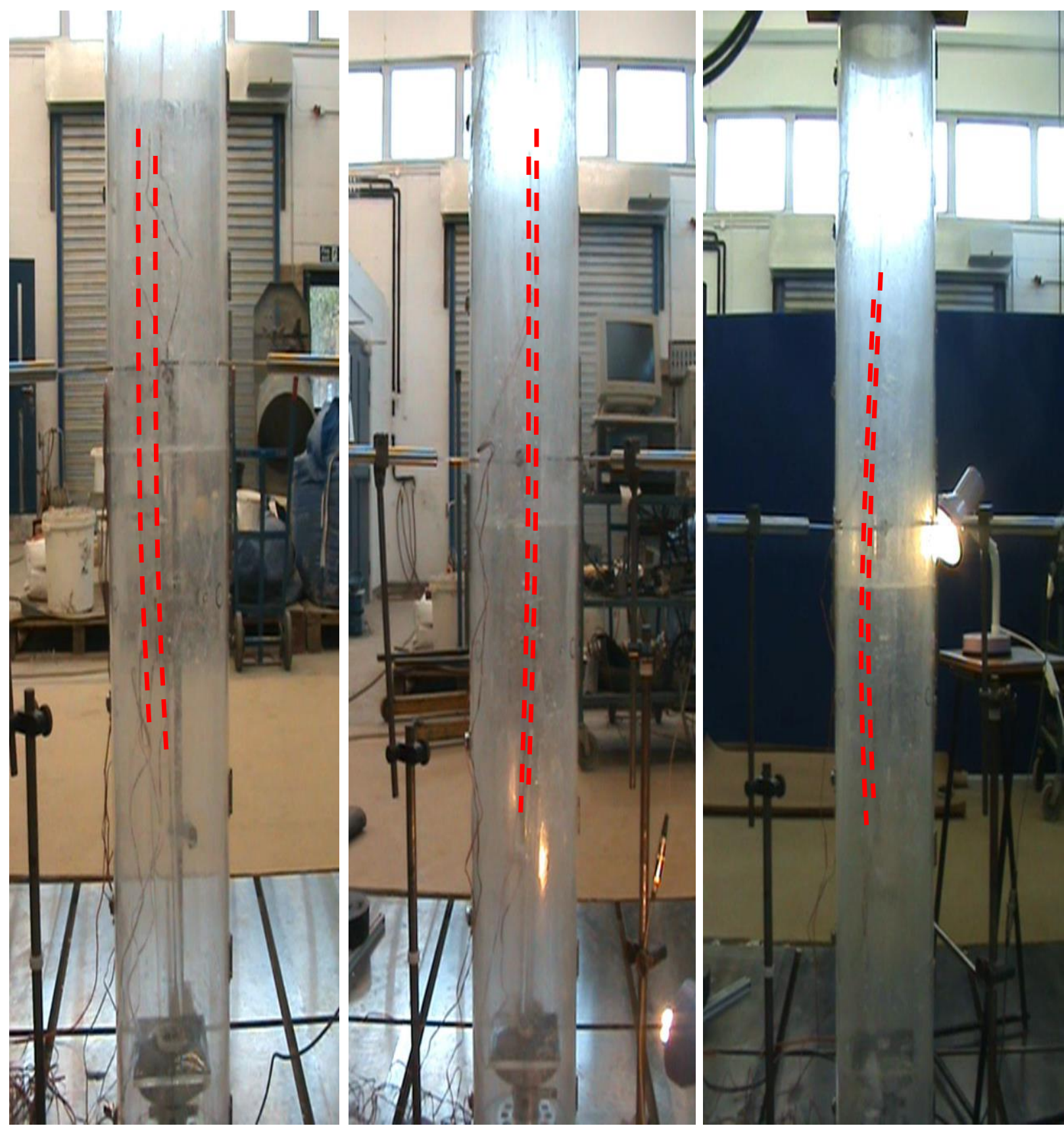

Fig. 7: Buckling mode shape in T3 (left), T4 (middle) and T5 (right) 
Based on the recorded video, for all BGC's specimens the initiation of the failure was due to buckling deformation. After buckling started to dominate the behaviour of the glass columns, the columns started to show considerable deflection while still carrying the maximum load. Under this condition, in specimens T6, part of the column splintered. At ultimate failure, the glass columns were immediately broken at the mid length of the columns while preserving one third of the glass pieces at both ends. Fig. 8 shows the typical buckling mode shapes of T6 and T7. Table 5 shows that the crack was recorded at a specific time for BGC. It was found that at least $50 \%$ of the remaining structural capacity was resisted by the bundled glass.

\section{Table 5}

Summary of time and load at first crack of BGC

BGC-Bundled-glass column; 24, 20-outer diameter; 2.5, 1.8-wall thickness

\begin{tabular}{ccccccc}
\hline No. & Type & Specimen & $\begin{array}{c}\text { Time at } \\
\text { first } \\
\text { crack } \\
(\mathrm{min})\end{array}$ & $\begin{array}{c}\text { Load at } \\
\text { first } \\
\text { crack } \\
(\mathrm{kN})\end{array}$ & $\begin{array}{c}\text { Time at } \\
\text { ultimate } \\
\text { failure } \\
(\mathrm{min})\end{array}$ & $\begin{array}{c}\text { Maximum } \\
\text { failure load } \\
(\mathrm{kN})\end{array}$ \\
\hline 25 & & & 16.32 & 6.94 & 18.33 & 14.15 \\
26 & & & 24.38 & 10.19 & 25.06 & 11.19 \\
27 & T6 & BGC- & 24.28 & 13.58 & 25.10 & 13.59 \\
28 & & & 21.33 & 3.98 & 25.52 & 12.56 \\
29 & & & 20.21 & 2.61 & 24.60 & 15.34 \\
\hline 30 & & & 8.52 & 5.71 & 14.40 & 8.01 \\
31 & & & 8.27 & 4.05 & 18.00 & 5.77 \\
32 & T7 & BGC- & 8.15 & 0.99 & 18.29 & 6.54 \\
33 & & $20 \_1.8$ & 7.40 & 0.41 & 20.50 & 7.03 \\
34 & & & 12.04 & 2.15 & 22.01 & 7.42 \\
\hline
\end{tabular}



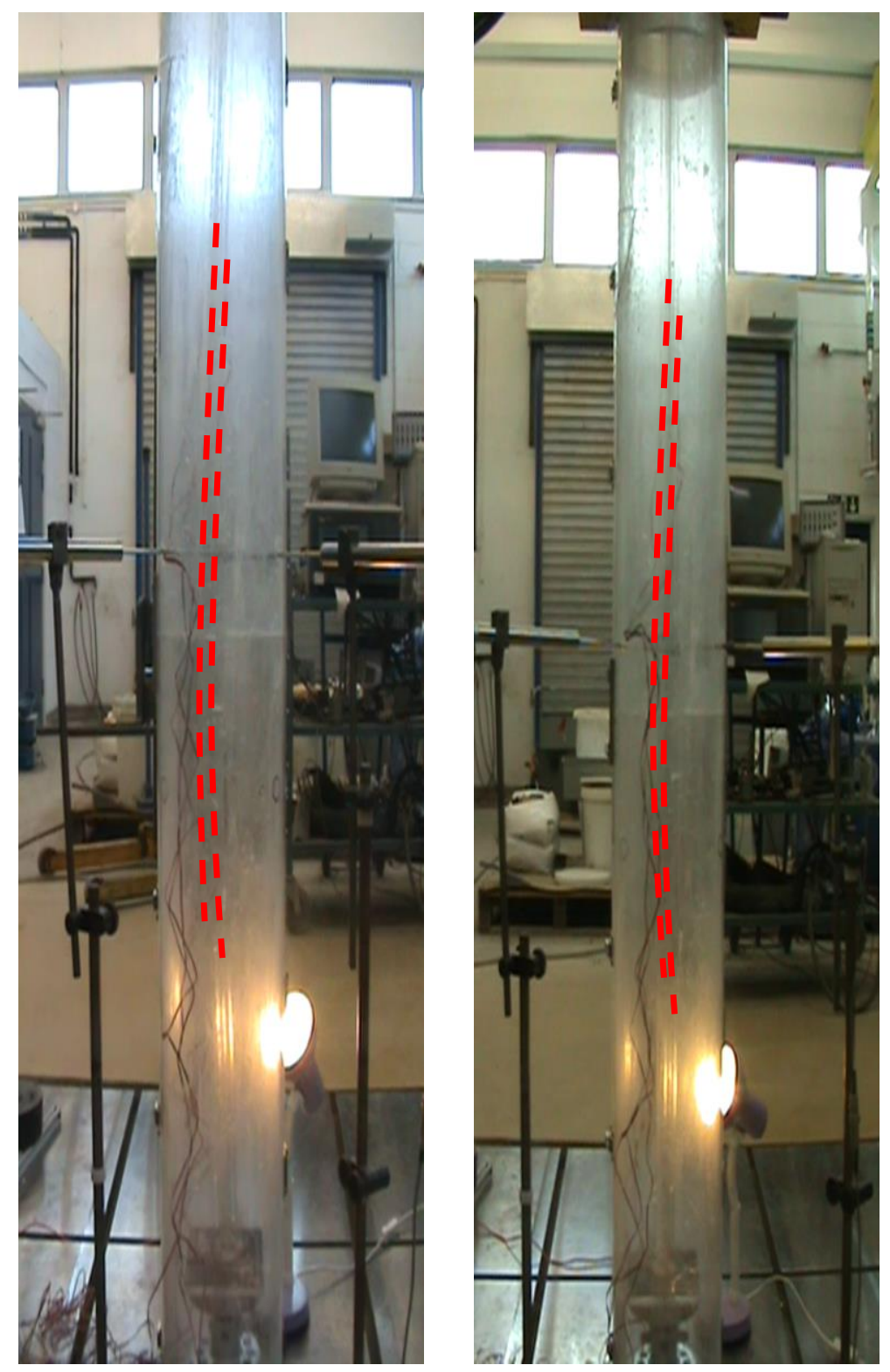

Fig.8: Buckling mode shape in T6 (left) and T7 (right) 


\subsection{Load carrying capacity}

A graph was plotted to portray the relationship between the maximum failure load and end axial shortening for a series of glass columns tested loaded in compression as shown in Fig.9. The slenderness ratio influenced the behaviour of the glass columns where the glass columns with a lower slenderness ratio were stiffer than those columns of a higher slenderness ratio. It was obvious that the $\mathrm{BGC}$ columns resisted a higher load than that obtained from the SGC of a similar diameter. The scatter for specimens that had a higher slenderness ratio was much lower than for those which had lower slenderness ratio. This was caused by the fact that the failure was governed by stability rather than by local peak stresses. It also showed that the glass column with a larger diameter was likely to have suffered more surface defects due to the increase in surface area.

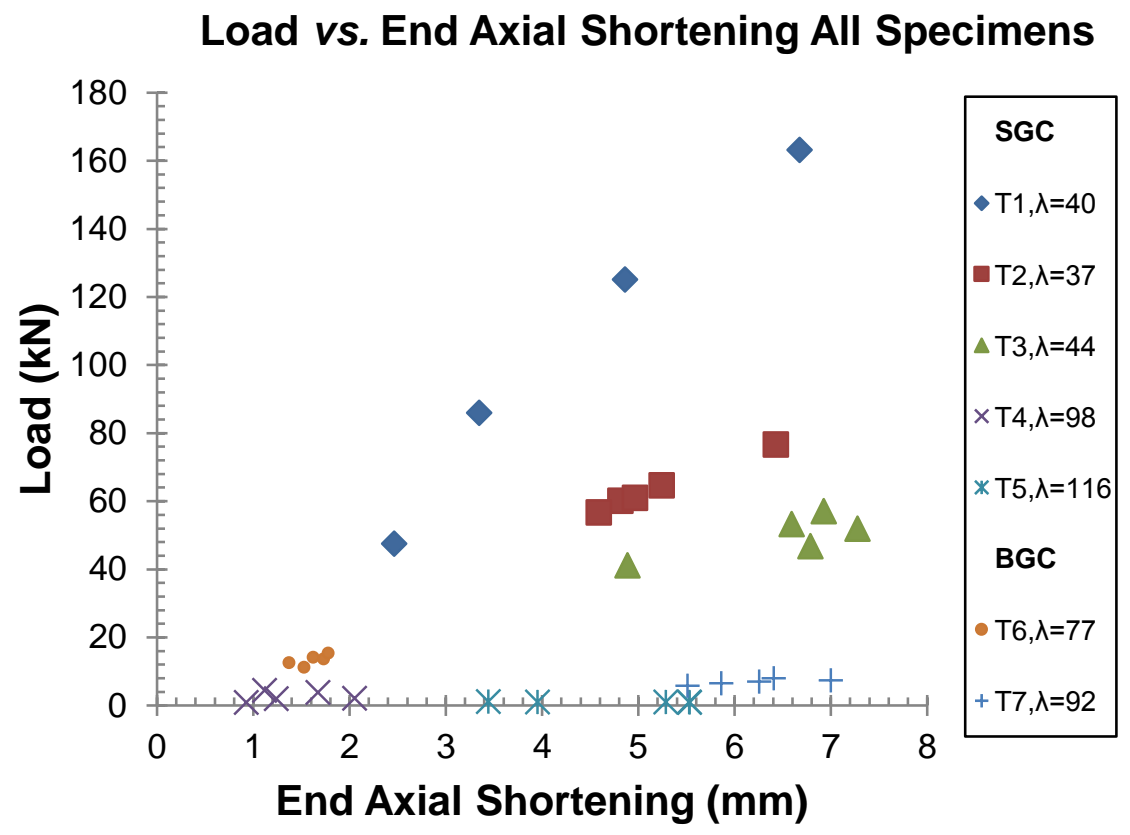

Fig. 9: Load vs. End Axial Shortening behavior of all specimens. 
The slenderness ratio is a non-dimensional value used to classify columns which is then used for design considerations. It is a ratio of the effective length, $\mathrm{L}_{e}$ of a column to the least radius of gyration of its cross section, r. In perfect steel compression members for example there are three typical slenderness values to classify a column. Columns with a slenderness ratio (Le/r) less than 40 are known as a short (stubby) column which will deform elastically until the material yield stress has been reached throughout the column cross section initiating plastic deformation without buckling. A slenderness ratio $\mathrm{Le}_{\mathrm{e}} / \mathrm{r}<40$ is also considered to be a low slenderness ratio. For $\mathrm{Le}_{\mathrm{e}} / \mathrm{r}>100$ or high slenderness ratio, a steel column is categorized as a long (slender) column in which the elastic buckling dominates the column failure mechanism. With an intermediate slenderness ratio $40<\mathrm{Le}_{\mathrm{e}} \mathrm{r}<100$, the column will approach plastic buckling failure. When considering columns made from glass, the intermediate slenderness ratio would be insignificant because glass is a brittle material where stress redistribution would not take the form of plastic deformation. Thus, for short and slender columns a similar behaviour to steel could be justified for glass columns with the provision that a short column would fail by cracking at the ends rather than yielding. From the experimental results, the slenderness ratio for each type of glass column tested was calculated and their failure mechanisms were summarized as shown in Table 6. Previous research results on the failure load of glass columns were also included to show the effects of different slenderness ratios on the structural behaviour of glass columns. It can be concluded that the slenderness ratio, $\mathrm{L}_{\mathrm{e}} / \mathrm{r}<40$ could be classified as short SGC which was subjected to progressive crushing at the ends of the glass columns. While, $\mathrm{Le}_{\mathrm{e}} / \mathrm{r}>40$ could be classified as slender SGC which was subjected to flexural buckling of the glass columns. 
Table 6

Data of slenderness ratio of several tested tubular glass columns.

\begin{tabular}{|c|c|c|c|c|c|c|c|}
\hline Researcher & $\begin{array}{c}\mathrm{L} \\
(\mathrm{mm})\end{array}$ & $\begin{array}{c}\text { Outer } \\
\text { diameter } \\
(\mathrm{mm})\end{array}$ & $\begin{array}{l}\text { Thickness } \\
(\mathrm{mm})\end{array}$ & $\begin{array}{l}\text { Support } \\
\text { condition }\end{array}$ & $\begin{array}{c}\text { Slenderness } \\
\text { ratio, } \lambda\end{array}$ & $\begin{array}{l}\text { Maximum } \\
\text { failure } \\
\text { load }(\mathrm{kN})\end{array}$ & $\begin{array}{c}\text { Failure } \\
\text { mechanism }\end{array}$ \\
\hline $\begin{array}{l}\text { Veer \& } \\
\text { Pastunink } \\
(1999) \\
\end{array}$ & 550 & 40 & 4.0 & Fixed & 22 & 35 & $\begin{array}{l}\text { Progressive } \\
\text { crushing from } \\
\text { the base }\end{array}$ \\
\hline This paper & 1500 & 60 & 2.2 & Fixed & 37 & 64 & $\begin{array}{l}\text { Progressive } \\
\text { crushing from } \\
\text { the base }\end{array}$ \\
\hline This paper & 1500 & 60 & 7.0 & Fixed & 40 & 105 & $\begin{array}{l}\text { Progressive } \\
\text { crushing from } \\
\text { the base }\end{array}$ \\
\hline $\begin{array}{l}\text { Veer } \\
\text { \&Pastunink } \\
(1999)\end{array}$ & 550 & 40 & 4.0 & Pinned & 43 & 110 & $\begin{array}{l}\text { Flexural } \\
\text { buckling }\end{array}$ \\
\hline This paper & 1500 & 50 & 1.8 & Fixed & 44 & 50 & $\begin{array}{l}\text { Flexural } \\
\text { buckling }\end{array}$ \\
\hline $\begin{array}{l}\text { Overend } \\
(2005)\end{array}$ & 1080 & 50 & 7.0 & Pinned & 70 & 50 & $\begin{array}{l}\text { Flexural } \\
\text { buckling }\end{array}$ \\
\hline This paper & 1500 & 24 & 2.5 & Fixed & 98 & 3 & $\begin{array}{l}\text { Flexural } \\
\text { buckling }\end{array}$ \\
\hline This paper & 1500 & 20 & 1.8 & Fixed & 116 & 1 & $\begin{array}{l}\text { Flexural } \\
\text { buckling }\end{array}$ \\
\hline $\begin{array}{l}\text { Bos\& Veer } \\
(2007)\end{array}$ & 555 & 12 & 3.5 & Pinned & 170 & 2 & $\begin{array}{l}\text { Flexural } \\
\text { buckling }\end{array}$ \\
\hline
\end{tabular}

\subsection{Buckling performance}

The lateral displacement behaviour at mid-length was investigated for specimens T3, T4 and T5 of SGC and specimens T6 and T7 of BGC since the initiation of failure for these columns was due to buckling. In order to extract the results of the lateral displacement, a careful consideration was made to obtain the maximum lateral displacement. This was done by solving the obtained maximum displacement from the LVDTs $\left(60^{\circ}, 180^{\circ}\right.$ and $\left.300^{\circ}\right)$ mathematically using the equation of a circle to locate the centroid of the circle at maximum 
failure. Fig.10 shows the load versus lateral displacements behaviour of SGC and BGC measured at the mid-length of the glass columns. The failure in the glass columns was governed by global buckling. No local buckling occurred since stress redistribution was not possible in glass. In this test, the effect of eccentricity was not taken into account since the load was assumed to be applied concentrically. With the SGC, the magnitude of the buckling, which was measured in terms of mid-length deflections, was higher in specimen T3 compared with specimens T4 and T5. The columns had sustained a higher peak load which led to high stress concentrations on the glass surface and the magnitude of the mid-length deflections was further increased. The columns failed by shattering catastrophically due to the high stress concentrations. The curves from the mid-length deflections in specimens T4 and T5 were similar. Meanwhile, the mid-length deflection curves for both specimens T6 and T7 displayed a similar pattern. The magnitude of the mid length deflections increased rapidly in these specimens due to their low capability to buckle. All specimens showed a half sine wave buckling shape.

Theoretically, the strength of BGC should be greater than the sum of its constituent SGC. However, in this case, the effectiveness of the structural silicone sealant incorporated into the structure to distribute loads was investigated. The investigation was carried out based on the results of the maximum failure load and the composite action of BGC compared to the SGC as shown in Table 7. Based on Table 7, it can be concluded that BGC achieved full composite action since for BGC-24 mm, $5.08>4.92$ and for BGC-20mm, $6.81>4.78$. Overall, it showed that the adhesive with a low modulus was effective in connecting the tubes and achieving the composite stiffness of the multiple $1500 \mathrm{~mm}$ long glass columns. The chosen structural silicone 
sealant proved that it could be successfully applied in structural glass applications fulfilling the design requirements.

Table 7

Effective measurement of adhesive connections.

\begin{tabular}{|c|c|c|c|c|c|}
\hline Dia. & Type & $\mathrm{A}$ & I & $\mathrm{P}_{\text {exp }}$ & $\mathrm{P}_{\mathrm{cr}}$ \\
\hline \multirow[t]{2}{*}{$\mathrm{mm}$} & & $\mathrm{mm}^{2}$ & $\mathrm{~mm}^{4}$ & $\mathrm{kN}$ & $\mathrm{kN}$ \\
\hline & SGC & 168.86 & 9888.90 & 2.63 & 11.10 \\
\hline \multirow[t]{3}{*}{24} & BGC & 506.58 & 48650.70 & 13.37 & 54.63 \\
\hline & BGC/SGC & - & 4.92 & 5.08 & 4.92 \\
\hline & SGC & 102.92 & 4303.03 & 1.02 & 4.83 \\
\hline \multirow[t]{2}{*}{20} & BGC & 308.76 & 20583.10 & 6.95 & 23.11 \\
\hline & BGC/SGC & - & 4.78 & 6.81 & 4.78 \\
\hline
\end{tabular}

$\mathrm{A}=$ area, $\mathrm{I}=$ second moment of area, $\mathrm{P}_{\mathrm{exp}}=$ experimental load, $\mathrm{P}_{\mathrm{cr}}=$ Euler load 
Load vs. Lateral Displacement at Mid Length of T3

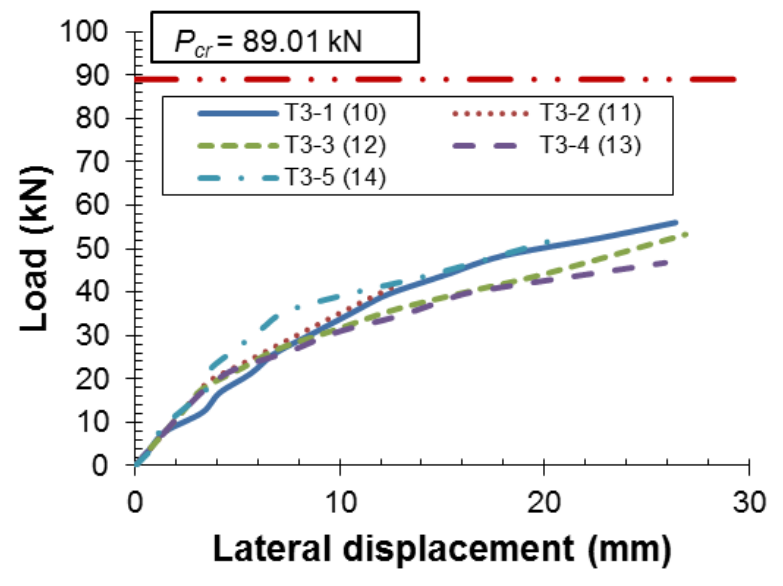

Load vs. Lateral Displacement at Mid Length of T5

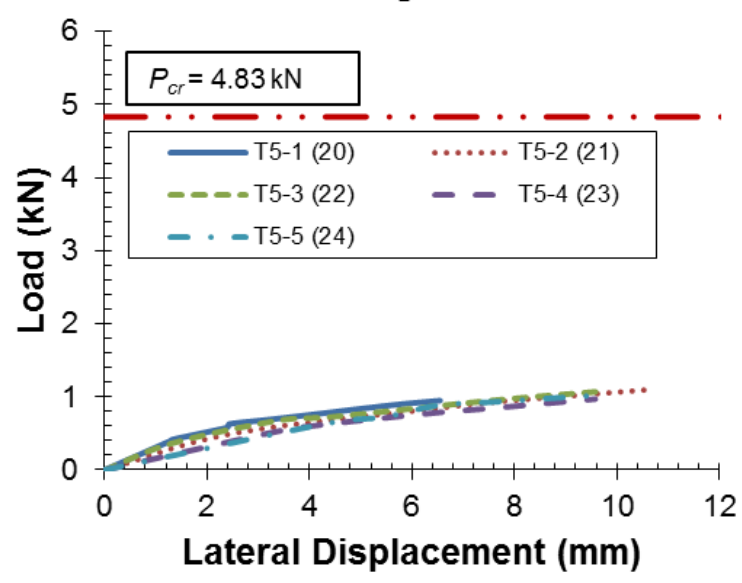

Load vs. Lateral Displacement at Mid Length of T7

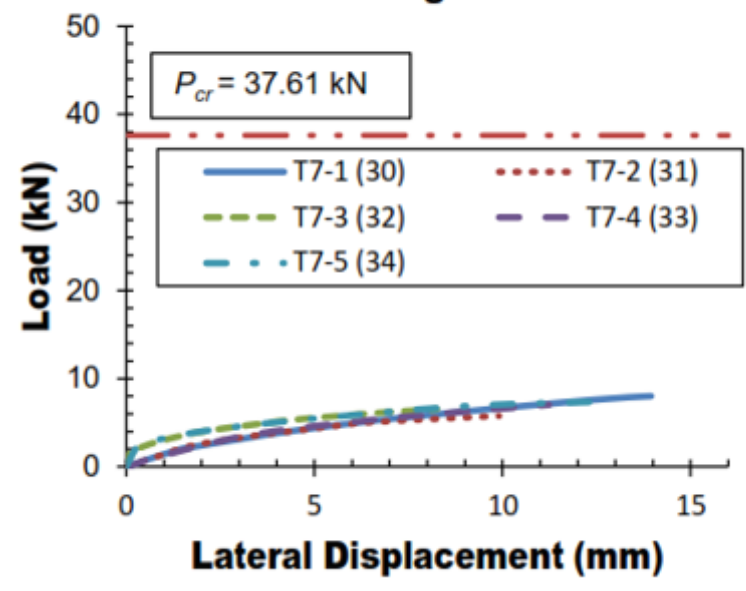

Load vs. Lateral Displacement at Mid Length of T4

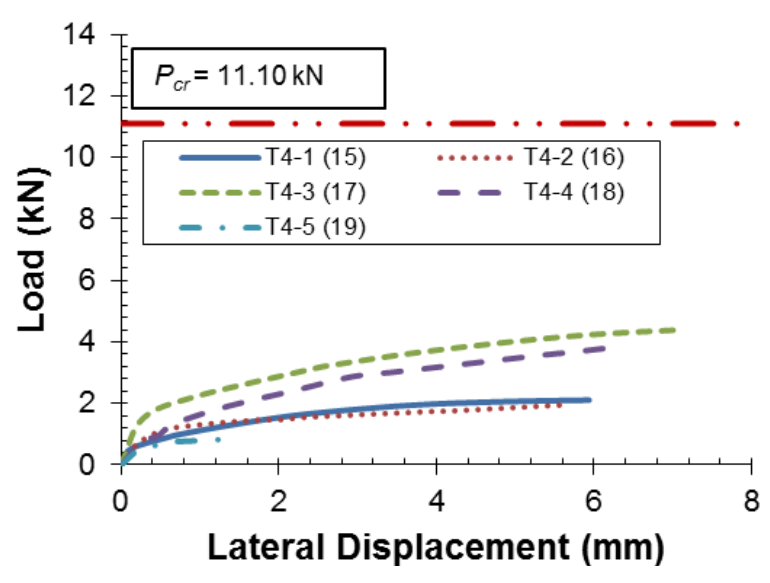

Load vs. Lateral Displacement at Mid Length of T6

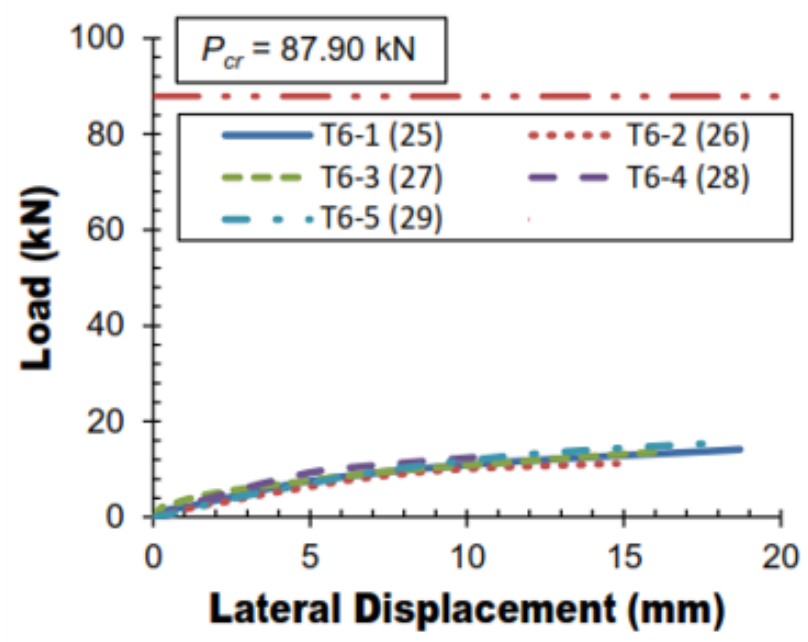

Fig. 10: Load vs. lateral displacement of SGC and BGC failed due to buckling 


\section{4. $\quad$ Finite element analysis (FE)}

\subsection{General approach}

The finite element (FE) method is generally considered to be one of the most versatile methods to examine the behaviour of a structure. By using the FE method, solutions for complicated geometry, loading and boundary conditions can be obtained quite readily. An analysis model of a tubular glass column loaded with a compressive force described earlier was developed with the finite element software ABAQUS version 6.10. The numerical modelling consists of the following procedure; (i) construction of the model: types of element, material properties, boundary conditions, meshing density and solution procedure, (ii) results: load-axial displacement and load-lateral displacement at the middle of the column and (iii) discussion: comparison between experiment and analysis results.

In order to investigate the buckling behaviour of glass columns, a geometrically non-linear analysis was carried out. This procedure was achieved by using the modified Riks method. The Riks method is a provided step analysis tool in ABAQUS/Standard to solve buckling and post-buckling problem either in a stable or unstable state of condition. Riks or also known as arc-length method was developed from the established Newton-Rhapson method. In the Newton-Rhapson approach, an incremental-iterative procedure is adopted to obtain a solution point along the load path. The load is subdivided into a series of load increments which can be applied over several load steps. Before each solution, the Newton-Rhapson method evaluates the out-of-balance load vector which is the difference between the restoring forces (the loads corresponding to the element stresses) and the applied loads. A linear solution is performed, using the out-of-balance loads to check for convergence. If the convergence criterion is not satisfied, the out-of-balance load vector is re- evaluated, the stiffness matrix is updated and a 
new solution is obtained. This iterative procedure continues until the problem converges. In some non-linear static analyses, if the Newton-Rhapson method is used alone, the tangent stiffness matrix may become singular (or non-unique) causing severe convergence difficulties. Such occurrences include non-linear buckling analysis in which the structure either collapses completely or 'snaps through' to another stable configuration. For such situation, the arc-length method is useful to avoid bifurcation points and track unloading hence suitable for this research. The arc-length method causes the Newton-Rhapson equilibrium iterations to converge along an arc. The procedure of analysis undertaken is described precisely in the next section.

\subsection{Element selection}

The element type S4R was used to construct the 3D-element glass column structure since it was a conventional robust general purpose element and suitable for wide applications. Most researchers in finite element analysis for glass have selected shell element due to their ability to reduce the computational effort (convergence time and disk space) without losing the necessary information for simulating the buckling behavior. S4R is a 4-node doubly curved linear quadrilateral shell element with finite-membrane-strain and reduced- integration. The element was suitable for its ability to accommodate curved geometry.

\subsection{FEA model assembly and mechanical properties}

The analytical formulations for plates, beams or columns are subjected under the hypotheses of ideal mechanical material behaviour as well as boundary and loading conditions. In the FE model, glass was described as a linear, indefinitely elastic, isotropic material with density, $\rho=2490 \mathrm{~kg} / \mathrm{m}^{3}$, Young's modulus, $\mathrm{E}=64 \mathrm{GPa}$ and Poisson's ratio, $v=0.2$. The 
structural silicone sealant is characterized by a shear modulus which is several orders of magnitude smaller than that of glass. Interlayer capacity of transferring shear stresses between the adjacent glass layers is influenced by many factors such as temperature, load duration and load level. Numerical models often consider an interlayer made of a viscoelastic material with variable shear modulus. However, in this work, the interlayer is considered as a linear elastic material with constant properties during the analysis. The interlayer is modelled as an elastic material able to transmit only shear actions to the attached glass layers, whereas in-plane normal stresses and deformations into the material are assumed to be negligible. For the interlayer, a linear elastic material was used, with the Poisson's ratio, $v=0.49$ and the density, $\rho=1100$ $\mathrm{kg} / \mathrm{m}^{3}$. Ideally, the end conditions for the glass column were fixed-fixed supports. Two different types of boundary conditions were used to simulate the analysis. The ends were divided into a fixed end and a movable end. At the fixed end, the translational degrees of freedom in 1, 2, 3 directions (U1, U2, U3) as well as rotational degrees of freedom in $1,2,3$ directions $(\theta 1, \theta 2, \theta 3)$ were restrained to be zero. At the movable end, while all rotational degrees of freedom in all directions were restrained to be zero, as well as the translational degrees of freedom in 1 and 2 , but U3 were free as the longitudinal direction was subjected to displacement. In the meshing procedure, it was important to use the optimum mesh density to obtain results with a good accuracy without using excessive computer time. In order to achieve the optimum mesh density, element mesh refinement was carried out. The element mesh was established by using edge seed for a different number of elements. The mesh refinement was carried out until a constant value was achieved and the most effective time in running the analysis was the criteria of a good mesh for the analysis. Eigenvalue buckling analysis was performed on the model to obtain the optimum mesh density by comparing the analysis buckling load with the theoretical Euler 
buckling load. In the analysis, the critical buckling loads were obtained from the resultant eigenvalues for each type of glass column respectively. Equation 1 was extracted from the ABAQUS example manual and was used to calculate the critical buckling load:

$$
P_{c r}=E \times a \times \frac{\Delta L}{L} \times A
$$

where $P_{c r}$ is the critical buckling load, E is the Young's modulus of the material, $a$ is the eigenvalue, $\Delta L$ is the input of the displacement, $L$ is the length of the glass column and $A$ is the area of cross section. The comparison of finite element buckling load and theoretical buckling load for various mesh densities are presented in Table 8(a) and (b). The best mesh quality in the analysis for $60 \mathrm{~mm}$ diameter tubular glass was obtained using only 40 elements.

Table 8

Mesh density analysis of the finite element model for $60 \mathrm{~mm}$ diameter tubular glass column

\begin{tabular}{|c|c|c|c|}
\hline \multicolumn{5}{|c|}{ (a)T1: SGC-60_7.0 } \\
\hline $\begin{array}{c}\text { No. of } \\
\text { elements }\end{array}$ & $\begin{array}{c}\text { FE } \mathrm{P}_{\text {cr }} \\
(\mathrm{kN})\end{array}$ & $\begin{array}{c}\text { Theoretical } \\
\mathrm{P}_{\mathrm{cr}}(\mathrm{kN})\end{array}$ & $\begin{array}{c}\text { \% error } \\
\text { S4R }\end{array}$ \\
\hline 10 & 403.50 & 467.58 & 14 \\
\hline 20 & 438.64 & $"$ & 6 \\
\hline 30 & 445.31 & $"$ & 5 \\
\hline 40 & 447.65 & $"$ & 4 \\
\hline 50 & 448.74 & $"$ & 4 \\
60 & 449.33 & $"$ & 4 \\
70 & 449.71 & $"$ & 4 \\
\hline 80 & 449.95 & $"$ & 4 \\
\hline 90 & 450.10 & $"$ & 4 \\
\hline 100 & 450.22 & $"$ & 4 \\
\hline
\end{tabular}

\begin{tabular}{|c|c|c|c|}
\hline \multicolumn{4}{|c|}{ (a)T1: SGC-60_7.0 } \\
\hline $\begin{array}{c}\text { No. of } \\
\text { elements }\end{array}$ & $\begin{array}{c}\text { FE P } P_{\text {cr }} \\
(\mathrm{kN})\end{array}$ & $\begin{array}{c}\text { Theoretical } \\
\mathrm{P}_{\mathrm{cr}}(\mathrm{kN})\end{array}$ & $\begin{array}{c}\% \text { error } \\
\text { S4R }\end{array}$ \\
\hline 10 & 403.50 & 467.58 & 14 \\
\hline 20 & 438.64 & $"$ & 6 \\
\hline 30 & 445.31 & $"$ & 5 \\
\hline 40 & 447.65 & $"$ & 4 \\
\hline 50 & 448.74 & $"$ & 4 \\
\hline 60 & 449.33 & $"$ & 4 \\
\hline 70 & 449.71 & $"$ & 4 \\
\hline 80 & 449.95 & $"$ & 4 \\
\hline 90 & 450.10 & $"$ & 4 \\
\hline 100 & 450.22 & $"$ & 4 \\
\hline
\end{tabular}

In the analysis the Static-Riks post buckling analysis in ABAQUS was adopted to run the simulation with regards to the arc-length method mentioned earlier. In the arc-length method, the load factor at each of the iterations is modified so that the solution follows some specified path 
until convergence is achieved. This condition prevents divergence even when the slope of loaddeflection curve becomes zero or negative. An initial imperfection was introduced in the model. It can be defined as a linear superposition of buckling eigenmodes obtained from the eigenvalue buckling analysis with a specified imperfection parameter. A geometric imperfection was introduced to the 'perfect' model structure to trigger the response in the buckling mode before the theoretical critical load was reached. The imperfection parameter used in the analysis was the initial deformation at mid length of the column. Since no geometrical measurement was taken at the mid length of the column, the analysis was carried out by taking a value of initial deformations of $\mathrm{L} / 2500$ [21] into consideration. The usual approach to simulate an imperfect structure was constructed under two stages; (i) First stage: An eigenvalue buckling analysis (*BUCKLE) was performed with ABAQUS/STANDARD on the 'perfect' model structure to establish probable collapse modes and to verify the convergence of the mesh density applied; and (ii) Second stage: A geometrically non-linear load-displacement analysis with the imperfection parameter was performed using the Riks method (*RIKS). The initial imperfection was included in the analysis by referring to the buckling modes generated in the first stage. The initial imperfection was applied using *IMPERFECTION in the analysis in the form of mode shape and scale factor. The first buckling mode was usually assumed to provide the most critical buckling load in the structure, thus was used and scaled to represent the imperfection parameter. The initial deformation value was taken as the scale factor for the imperfection to take effect.

\subsection{FE and experimental comparisons}

In the FE results as indicated in Fig.11 (b), high stress concentrations developed at each ends of the glass columns SGC. This was due to Poisson's ratio taking effect during loading 
which encountered friction between the glass and the boundary condition. Cracks are not established directly from a perfect surface, instead they are initiated from pre-existing Griffith flaws. Such flaws produce maximum stress at the crack tip. In regards to the mechanism occurring at the ends of the column, Griffith flaws were exposed to the high stress concentrations. This condition fulfilled the fracture energy concept and a crack initiated as shown in Fig.11(a). Fig.12 indicates the typical deformed shape of the glass columns which failed due to buckling from both experimental work and FEA. Tensile stress was developed at the mid length of the glass column as shown in Fig.12(b) due to the instability which dominates in this case. The deflection showed a half sine wave mode shape indicating the first buckling mode of the structure. The buckling deformation in the experimental work as shown in Fig.12 (a) was measured using the LVDTs which were installed around the circumference of the columns. 

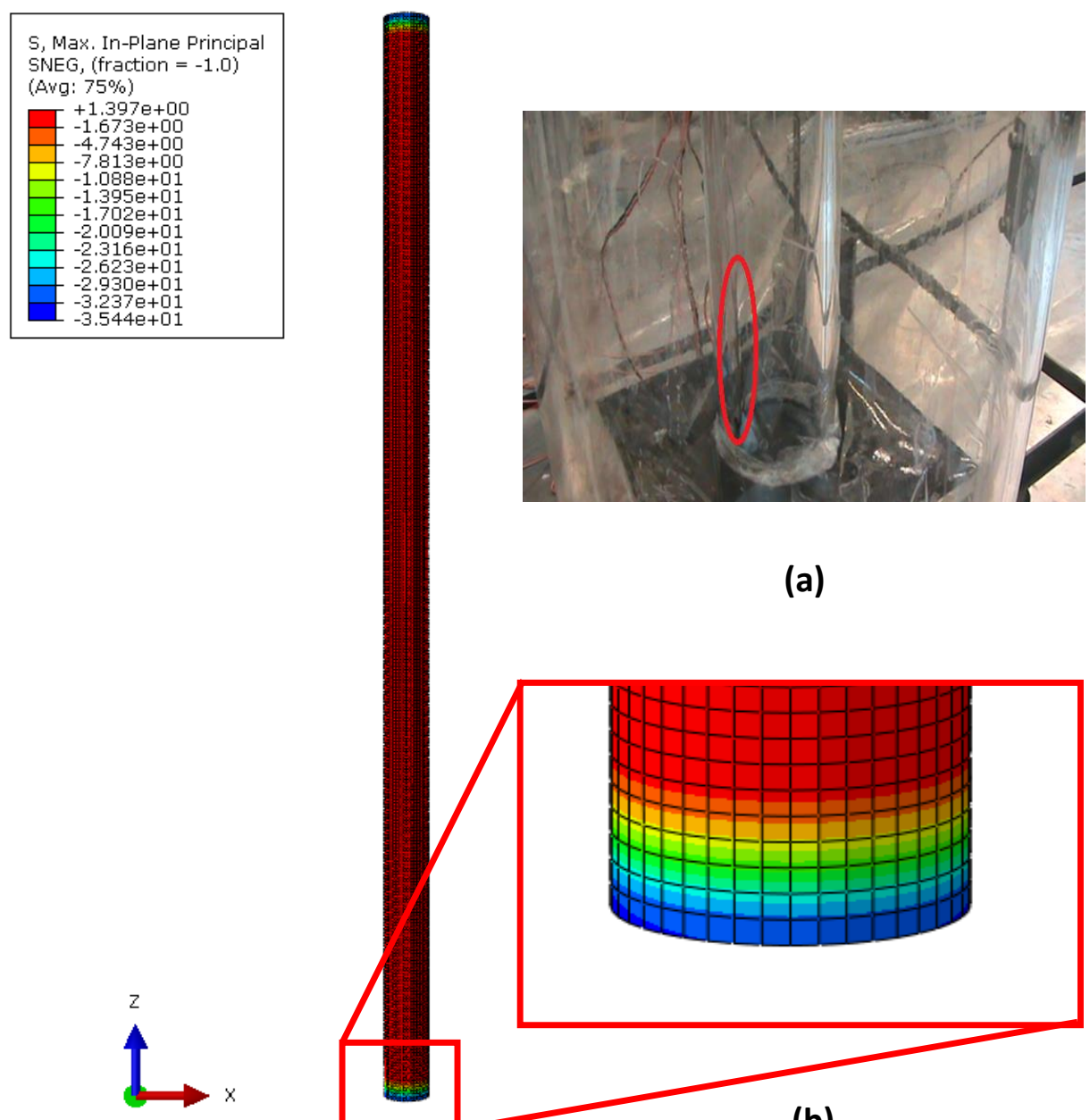

(a)

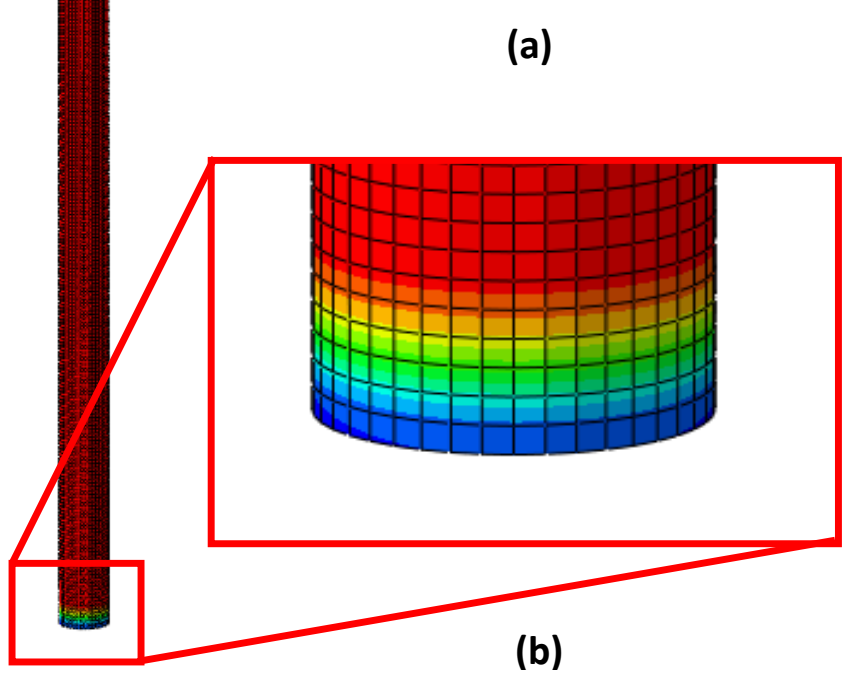

Fig.11: Typical deformed shape of the glass column SGC failed by crushing; (a) crack (in circle) occurred at the bottom of the glass column in the experimental work, (b) blue region signified the high stress concentrations where crack was believed to develop at the bottom of the glass column in the FE model. 


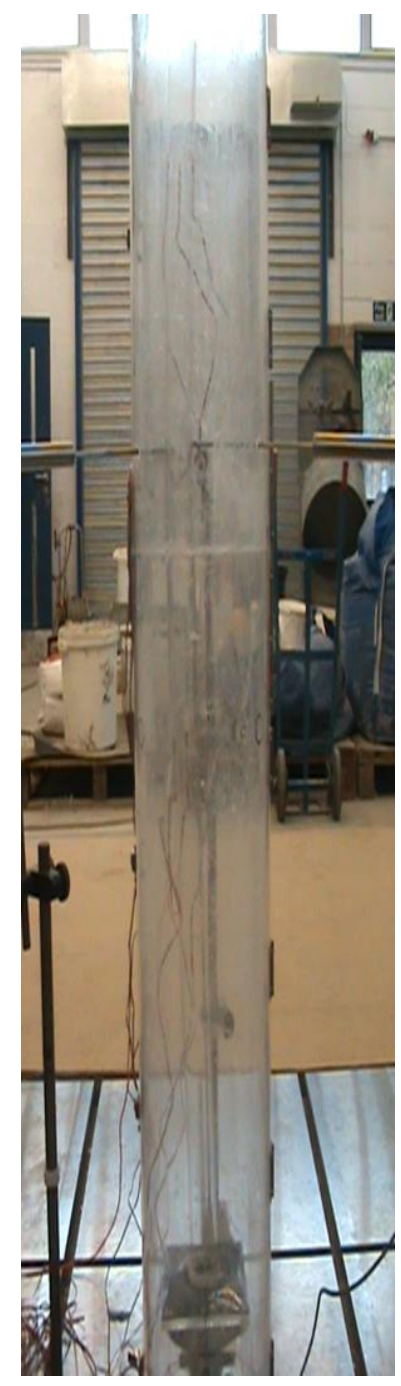

(a)
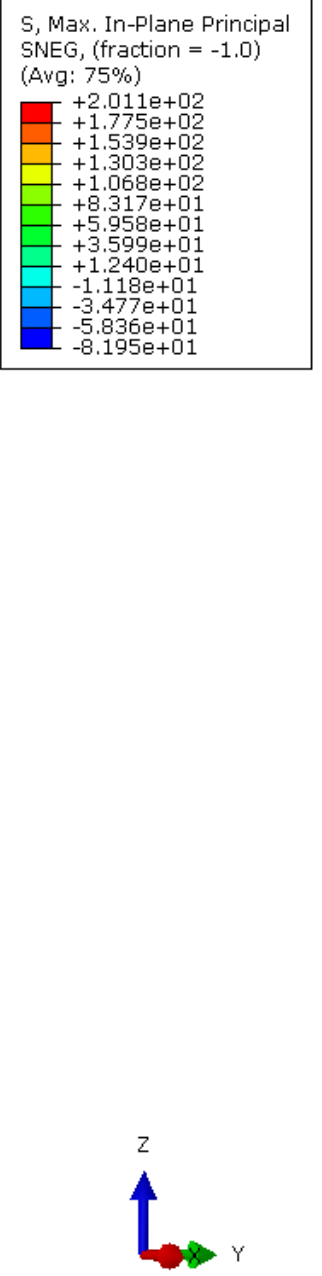

(b)

Fig.12: Typical deformed shape of the glass column SGC failed by buckling; (a) lateral deflection occurred at the mid length of the glass column in the experimental work, (b) red region at mid length signified the development of the tensile stress on the surface of the glass column showing the buckling shape in the FE model. 


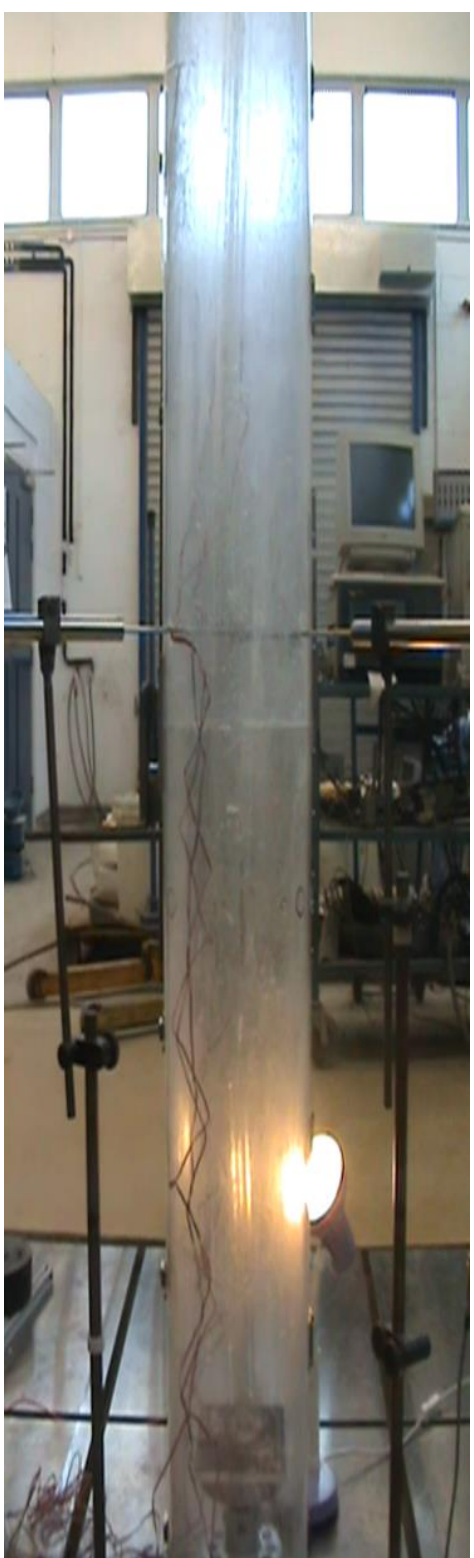

(a)
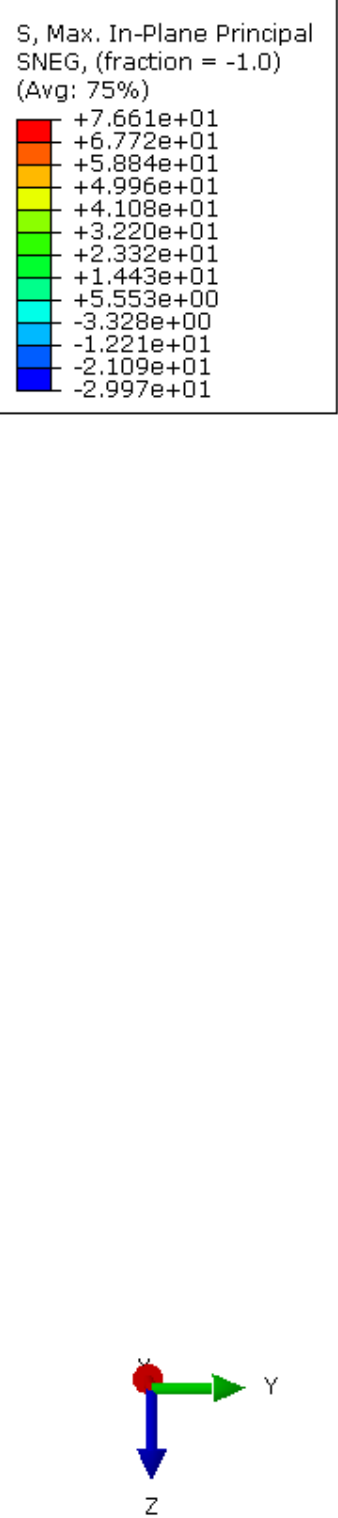

(b)

Fig.13: Typical deformed shape of the BGC failed by buckling; (a) lateral deflection occurred at the mid length of the glass column in the experimental work, (b) red region at mid length signified the development of the tensile stress on the surface of the glass column showing the buckling shape in the FE model. 
Fig.13 indicates the typical deformed shape of the glass columns that failed due to buckling in both the experimental work and FE. Tensile stress was developed at the mid length of the glass column as shown in Fig.13(b) due to the instability which occurred in this case. The deflection showed a half sine wave mode shape which was the first buckling mode of the structure. The buckling deformation in the experimental work as shown in Fig.13(a) was measured using the LVDTs which were installed around the circumference of the columns.

Comparisons of the FEA and experimental results are shown through the load-axial displacements plots of Fig.14. The load-axial displacements followed a similar pattern to the ones recorded from the tests. However, the linear gradients plotted in the FEA seemed to deviate from the linearity of the tests. Specimens which failed by crushing failure (T1 and T2) showed linear relationships between the load and axial displacements. Meanwhile, specimens which failed due to buckling deformation (T3, T4 and T5) showed initial linear relationships until peak failure load was reached. Post peak load behaviour was characterised by reducing load and nonlinear deflection, signifying buckling deformation. A simplified approach was adopted in FEA modelling in which the end supports were simplifed to avoid modeling the complicated hyperelastic behaviour of the rubber. However, this suggested that the FEA model still gave a good prediction of the behaviour of glass columns since both FEA and experimental results corresponded well. Comparisons of FEA and experimental results of BGC are shown through the load versus axial displacements plots of Fig.15. The behaviour from the resultant FEA did not correlate very well with the experimental results. The load versus axial displacement relationships of the glass columns showed initial linear relationships until it reached a peak failure load. Post peak load behaviour was characterised by reducing load and non-linear deflection, signifying buckling deformation. 
Load vs. Axial Displacement of

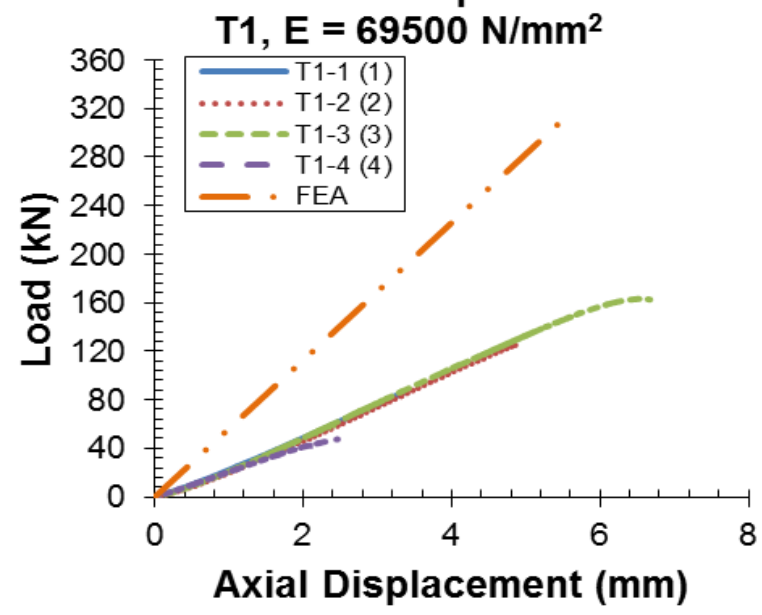

Load vs. Axial Displacement of

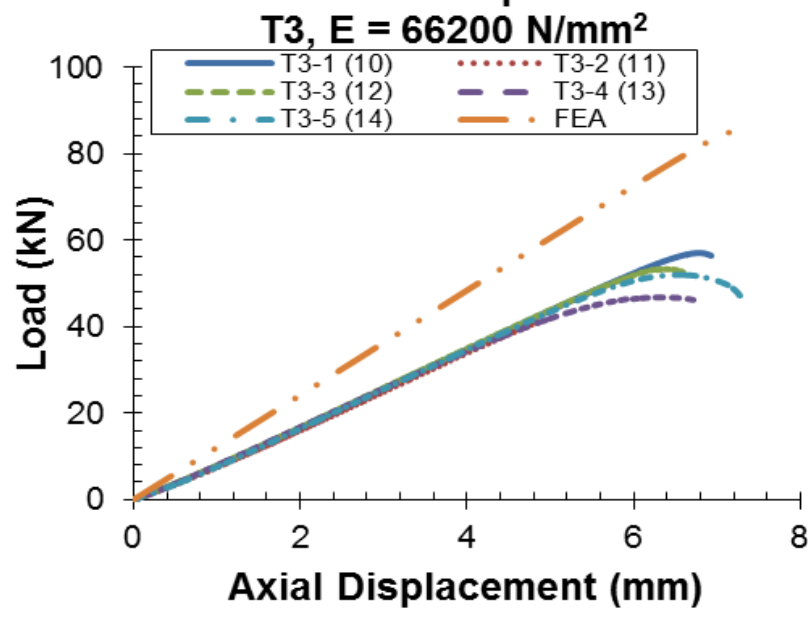

Load vs. Axial Displacement of

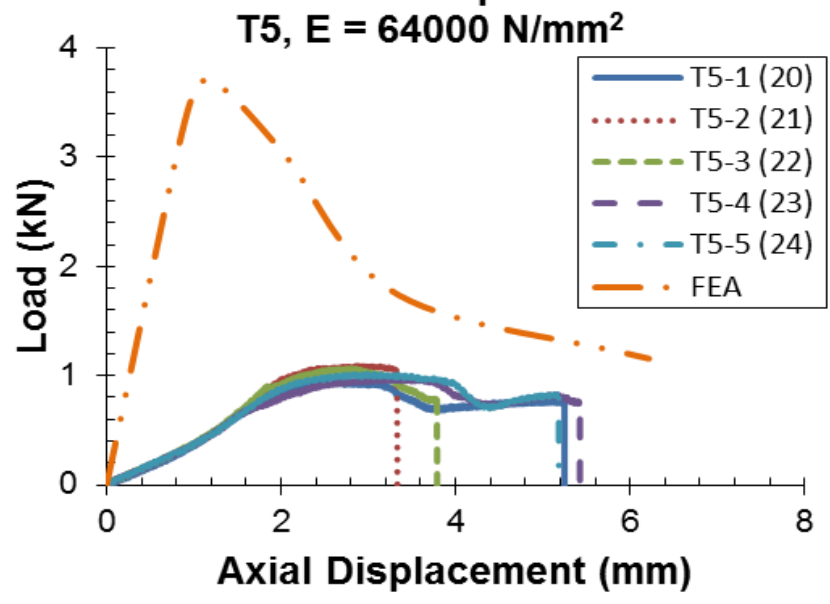

Load vs. Axial Displacement of

$\mathrm{T} 2, \mathrm{E}=62400 \mathrm{~N} / \mathrm{mm}^{2}$

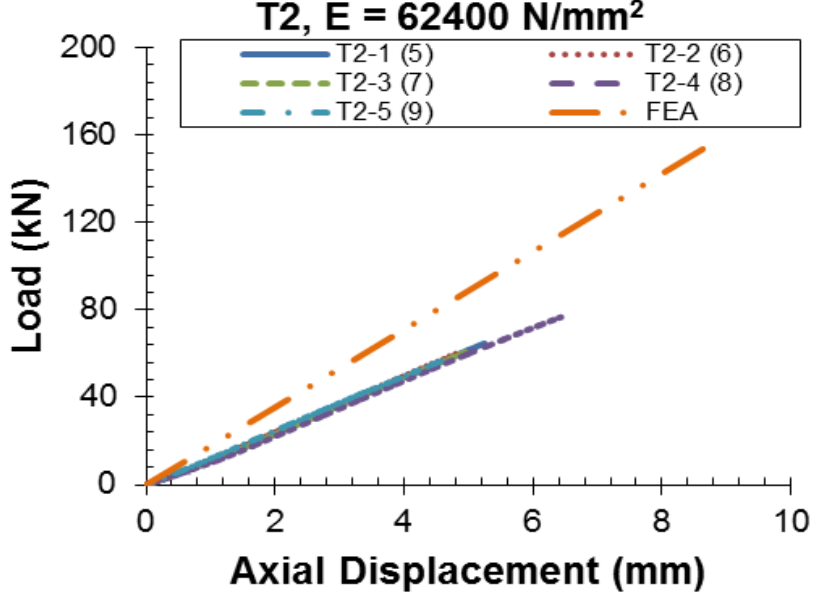

Load vs. Axial Displacement of $\mathrm{T} 4, \mathrm{E}=64000 \mathrm{~N} / \mathrm{mm}^{2}$

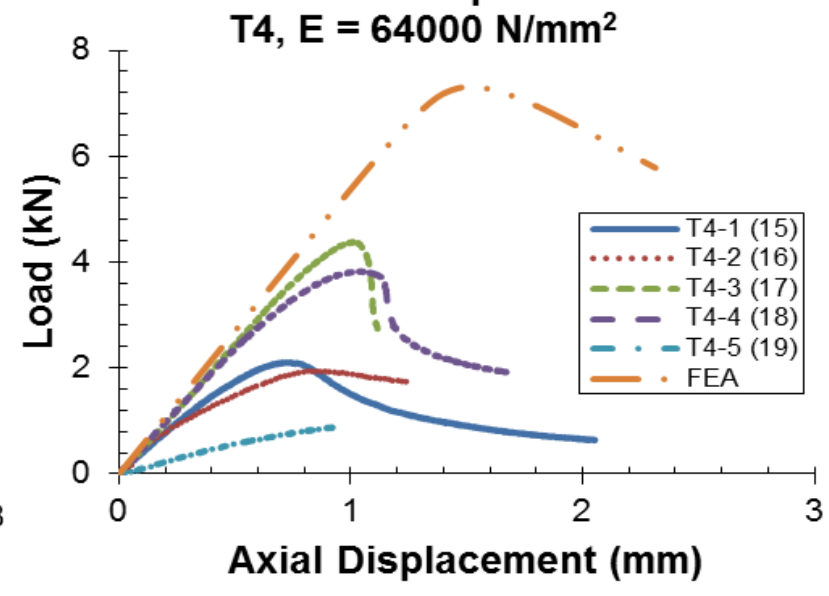

Fig.14: Comparison between experimental and FEA results of load versus axial displacement behaviour of SGC 

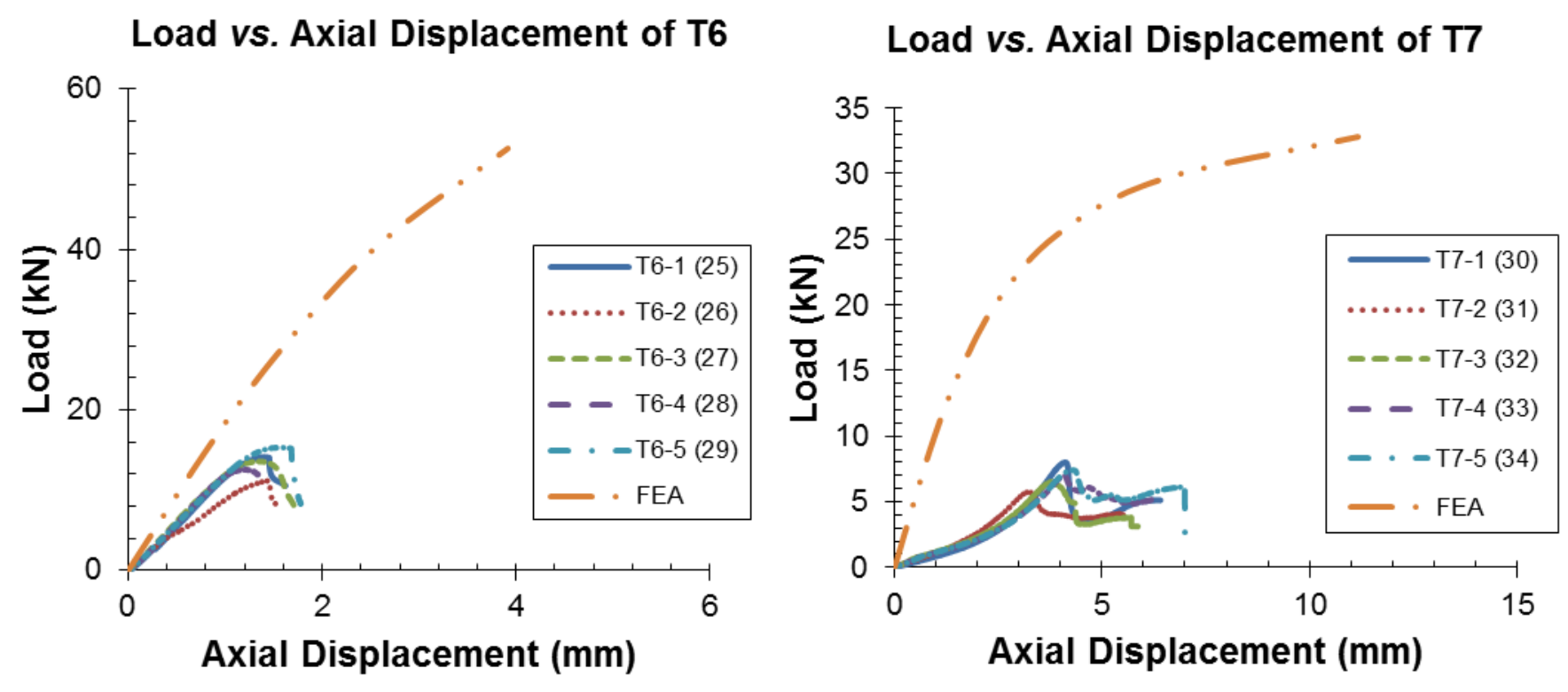

Fig.15: Comparison between experimental and FEA results of load versus axial displacement behaviour of BGC

Since this work followed the hypothesis of small displacements, elastic material behaviour for both glass and interlayer, and of interlayer characterized by constant mechanical parameters, further developments of the proposed model will account for geometric and material nonlinearity, together with the influence of load duration and load level on interlayer behaviour. Moreover, shear deformability will be taken into account by adopting more accurate FE formulations.

\section{Conclusion}

In conclusion, the strength of glass columns is dependent on the slenderness ratio of the columns. Crushing or buckling deformation governed the initial glass failure. This study suggests the slenderness ratio is related to the failure mechanism obtained from the test. The classification 
of slenderness ratio for glass columns has been determined which $\mathrm{Le} / \mathrm{r}<40$ can be classified as a short column which is subjected to progressive crushing of the glass columns. While, Le/r > 40 can be classified as a slender column which is subjected to flexural buckling of the glass columns. The failure scatter for specimens that have higher slenderness ratio was much lower than for those which have a lower slenderness ratio. This was due to the fact that the glass failure was governed by stability rather than the local peak stresses. The relationships between the load and the axial displacements indicate a linear behaviour of the glass with an instantaneous failure without plastic deformation. The relationships between the load and the lateral displacements indicate a typical imperfect behaviour of a column member which an initial geometrical imperfection is present in a structure.

The factor which affected the strength of the glass was the presence of Griffith flaws in the glass surface. In order to predict glass strength by quantifying the number of Griffith flaws on the glass surface was almost impossible due to their random population. In addition, the existence of a large number of Griffith flaws of variable depth on the glass surface led to a complex interpretation of glass failure strength. However, an assumption needed to be made so an appropriate design consideration for structural glass could be applied. The variation of glass strength for identical pieces of glass was attributable to the existence of a random distribution of Griffith flaws on the glass surface. However, most of the research on glass has found that the glass failure did not follow a normal statistical distribution (main parameters: mean and standard deviation) due to the variability of the glass strength. In order to justify the variability of the glass strength, Weibull's statistical theory of failure is commonly being used. Weibull analysis is a method useful for fitting and analysing data from brittle materials to determine the probability of failure of glass. The method is appropriate even for the engineering analysis of an extremely 
small number of samples. The Weibull plot is inspected to determine how well the failure data fits a straight line. The two parameters $\left(\mathrm{m}\right.$ and $\left.\sigma_{0}\right)$ are determined experimentally by stressing a sample of the material until fracture occurs. The stress value $\sigma_{0}$ is the experimentally determined stress such that fracture occurs with a probability of 0.63 . The parameter $\mathrm{m}$ is known as the Weibull modulus, and provides a measure of the statistical spread of the distribution around $\sigma 0$. A good fit relates to the quality of the data obtained from the test. The plot gives the probability of failure of glass at a certain stress level. It was found that, i.e. for specimen T2, the data fitted well with the Weibull failure line as shown in Fig.16. This linear relationship is also found in other types of specimens. The relationship between the probability of failure and the stress was linear. The plots showed the benefits of knowing the probability of failure at a stress level applied to each of the glass types.

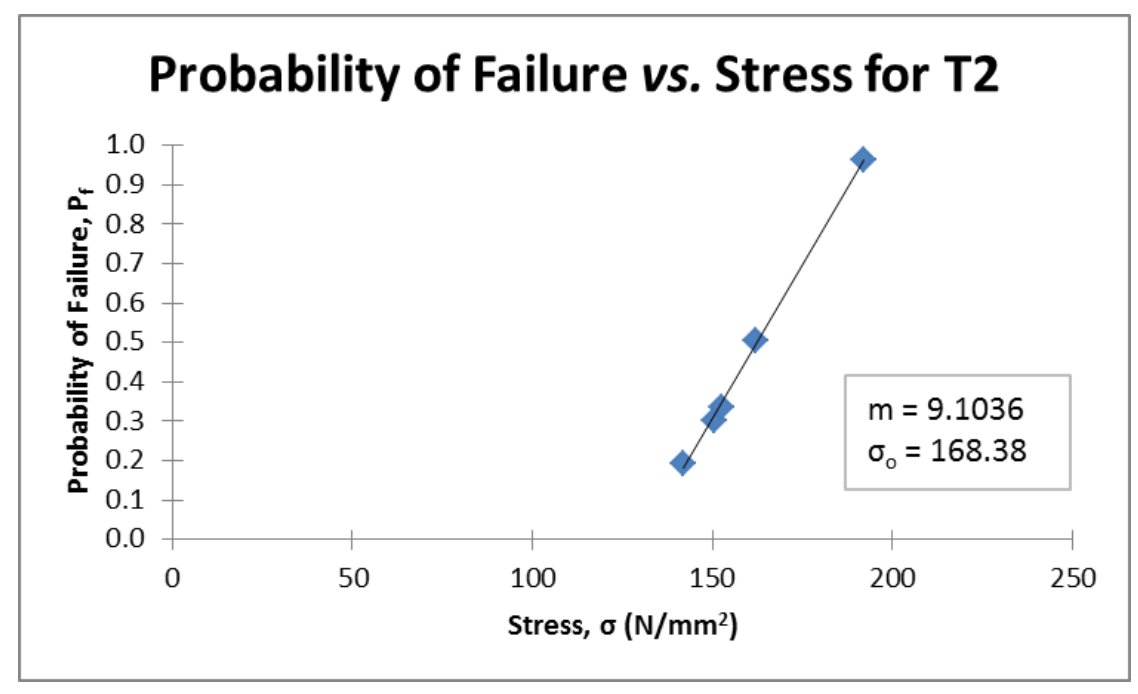

Fig.16: Weibull plot for SGC specimen T2 
Most of the FE results did not correlate very well to the experimental results since the FEA tends to overestimate the glass tube performance. However, the FE results still showing an acceptable load-axial displacement behaviour and the load-lateral displacement behaviour. Improvement needs to be done in the analysis method to obtain good agreement between the experimental and the FE. The parametric studies showed that the load carrying behaviour of tubular single glass columns under compression depended greatly on glass thickness which signified the influence of the geometric slenderness. Based on the simulation results, a column buckling curve was developed as shown in Fig.17. The column buckling curves for single glass columns under compression had an initial deformation of L/2500. However, the distribution points from the test should be improved by considering more specimens to be tested in the future. The BGC is an alternative for use as a structural glass column since the structural silicone sealants incorporated into the structure is capable of bonding multiple tubes together. The low modulus of the structural silicone sealant suggests that its capability to achieve full composite section in BGC is remarkable. 


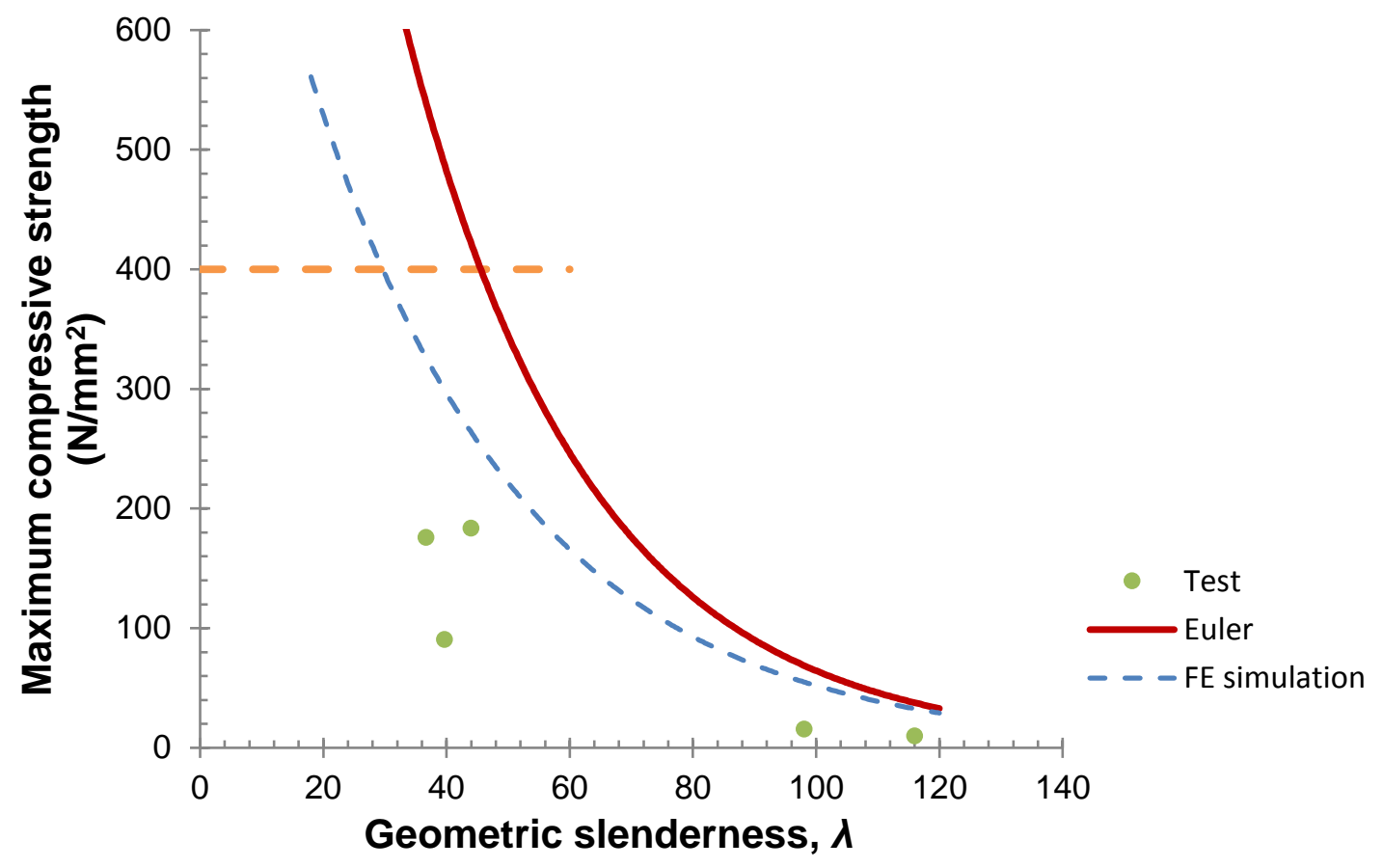

Fig. 17: Column buckling curves

\section{Acknowledgements}

We would like to thank Ministry of Higher Education of Malaysia as well as Universiti Teknologi MARA (UiTM) for their fund and Mr. Peter Haynes and Nigel Mobbs of the Heavy Structure Laboratory of University of Surrey for their endless support for this project. 